IRRADIATION OF SNAP SYSTEM ACTUATOR AND POSITION SENSOR ASSEMBLIES IN A VACUUM-NUCLEAR ENVIRONMENT

Sam J. Basham

William G. Rieder

William J. Zielenbach

H. Thomas Gruber

Joseph P. Allgeier

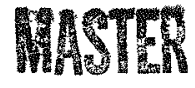




\section{DISCLAIMER}

This report was prepared as an account of work sponsored by an agency of the United States Government. Neither the United States Government nor any agency Thereof, nor any of their employees, makes any warranty, express or implied, or assumes any legal liability or responsibility for the accuracy, completeness, or usefulness of any information, apparatus, product, or process disclosed, or represents that its use would not infringe privately owned rights. Reference herein to any specific commercial product, process, or service by trade name, trademark, manufacturer, or otherwise does not necessarily constitute or imply its endorsement, recommendation, or favoring by the United States Government or any agency thereof. The views and opinions of authors expressed herein do not necessarily state or reflect those of the United States Government or any agency thereof. 


\section{DISCLAIMER}

Portions of this document may be illegible in electronic image products. Images are produced from the best available original document. 
TABLE OF CONTENTS

$\underline{\text { Page }}$

ABSTRACT . . . . . . . . . . . . . . . . . . . . . . . . 1

INTRODUCTION

EXPERIMENT DESIGN . . . . . . . . . . . . . . . . . . . . . . 2

Vacuum System • . . . . . . . . . . . . . . . . . . . . 2

Specimen Assemblies . . . . . . . . . . . . . . . . . . . . . . 4

Heat-Transfer Considerations . . . . . . . . . . . . . . . 9

FLUX-LEVEL CONSIDERATIONS AND MEASUREMENTS . . . . . . . . 9

Background . . . . . . . . . . . . . . . . . . . . . . 9

Dosimetry Techniques Used in Mock-Up Measurements . . . . . . . 10

Neutron Energy Spectra . . . . . . . . . . . . . . . 12

Neutron-Flux Distributions . . . . . . . . . . . . . . . 13

Gamma-Exposure-Rate Distribution . . . . . . . . . . . 13

Results of Mock-Up Operations . . . . . . . . . . . . . . . 13

Neutron Energy Spectra $\quad . \quad$. . . . . . . . . . . . . 13

Neutron-Flux Distributions . . . . . . . . . . . . . . 14

Gamma-Exposure-Rate Distribution . . . . . . . . . . . 16

Actuator Dosimetry . . . . . . . . . . . . . . 16

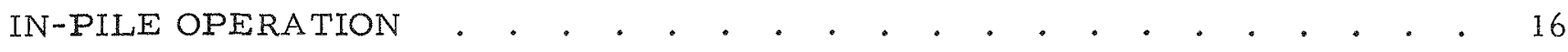

System Vacuum . . . . . . . . . . . . . . . . . . . . 18

Specimen Temperatures . . . . . . . . . . . . . . . . . 18

Specimen Performance Measurements . . . . . . . . . . . . . 26

Electrical Measurements . . . . . . . . . . . . . . . 26

Insulation Resistance . . . . . . . . . . . . . . 26

Resistance . . . . . . . . . . . . . . . . . 28

Input Impedance . . . . . . . . . . . . . . . . 28

Output Impedance . . . . . . . . . . . . . . . . 28

Summary of Measurement Results . . . . . . . . . . . . 28

Insulation Resistance . . . . . . . . . . . . . . 28

Resistance . . . . . . . . . . . . . . . . . . 31

Position Sensor Input and Output Resistance and Impedance . . 31

Summary of Operation Results . . . . . . . . . . . . . 31

Summary of Specimen Radiation Exposures . . . . . . . . . . . 31 


\title{
IRRADIATION OF SNAP SYSTEM ACTUATOR \\ AND POSITION SENSOR ASSEMBLIES IN A \\ VACUUM NUCLEAR ENVIRONMENT
}

\author{
Sam J. Basham \\ William G. Rieder \\ William J. Zielenbach \\ H. Thomas Gruber \\ Joseph P. Allgeier, Jr.
}

\begin{abstract}
$A B S T R A C T$
Two actuator and position sensor devices were irradiated to an integrated fastoneutron exposure of 2 and $4 \times 10^{18} \mathrm{n} / \mathrm{cm}^{2}$ in a bigb-vacuum environment $\left(10^{-5}\right.$ torr $)$ at temperatures of 500 to $700 \mathrm{~F}$ to obtain radiation.effects data for the Atomics International SNAP program. Detailed measurements of the nuclear environment were made to aid in the study of radiation damage of the specimens. Temperatures and vacuum levels were monitored continuously. Actuator opera. tional performance was monitored periodically as were the characteristics of components (insulation resistance, resistance, impedance) to establisb degrada. tion rates and damage thresholds.
\end{abstract}

\section{INTRODUCTION}

As part of the "Environmental Irradiation of Materials and Components" program being conducted at Battelle under the auspices of Atomics International, Division of North American Aviation, two actuator assemblies were selected for evaluation of their life and operating characteristics. Each unit consisted of a position sensor, an auxiliary position sensor, a brake assembly, and a position actuator (a stepping-type drive motor). The units were to be exposed to the following conditions

$\begin{array}{ll}\text { Vacuum } & 1 \times 10^{-5} \text { torr } \\ \text { Temperature } & \\ \quad \begin{array}{l}\text { Actuator } \\ \text { Position Sensor }\end{array} & 720 \mathrm{~F} \\ \text { Integrated fast-neutron flux } & 420 \mathrm{~F} \\ \text { Total gamma exposure } & 4.06 \times 10^{18} \mathrm{n} / \mathrm{cm}^{2}\end{array}$

Previous experiments in this program were conducted in the two vacuum systems at the Battelle Research Reactor. These were four high-flux irradiations (HF-I through HF-4 described in Report No. BMI-X-310) and five low-flux experiments (LF-1 through $L F-3, I L F-1$, and ILF-2 described in Report No. BMI-X-290). 
The experimental program consisted of the following phases:

(1) Procurement and fabrication of the actuator assemblies by Atomics International

(2) Selection of the experimental conditions by Atomics International in conjunction with Battelle

(3) Reactor mapping to determine flux distribution and gamma exposure rates

(4) Experiment design

(5) Experiment assembly and installation in the high-flux, high-vacuum facility at the Battelle Research Reactor

(6) Conduct of the experiment with continuous temperature and vacuumlevel monitoring and periodic actuator-performance monitoring to obtain data to establish degradation rates and damage thresholds and to evaluate actuator life.

(7) Postirradiation evaluation of experiment dosimetry.

This report covers all aspects of design, operating procedures, and specimenradiation-level measurements. The irradiated actuators were operated in the Battelle Hot Cell Facility and were disassembled there. The results of this work are not presented in this report.

\section{EXPERIMENT DESIGN}

Vacuum System

Figure 1 shows the permanent high-flux vacuum facility at the BRR utilized for this experiment. This facility, constructed of aluminum pipe, extends from the movable bridge over the reactor pool to a pocket formed by the fuel elements at the front face of the core. The principal elements of the system are (1) a test section of 8-in. pipe adjacent to the core, (2) a tee-section, (3) a 6-in. pipe leading to the vacuum pump, (4) a seal plate between the tee-section and the section of pipe housing the leads, (5) the 4-in. line housing the thermocouple, heater, and performance-measurements leads, and (6) a 2-1/2-in. pipe containing the ionization-gage leads.

The test chamber was evacuated by a 6-in. diffusion pump backed by a two-stage mechanical pump; the pumps also maintained chamber vacuum during the irradiation. A liquid-nitrogen-cooled trap was located on top of the diffusion pump. System vacuum was sensed by two ionization gages located near the tee-section, by two ion gages near the diffusion pump, and by an ionization gage in the upper part of the test chamber. In 


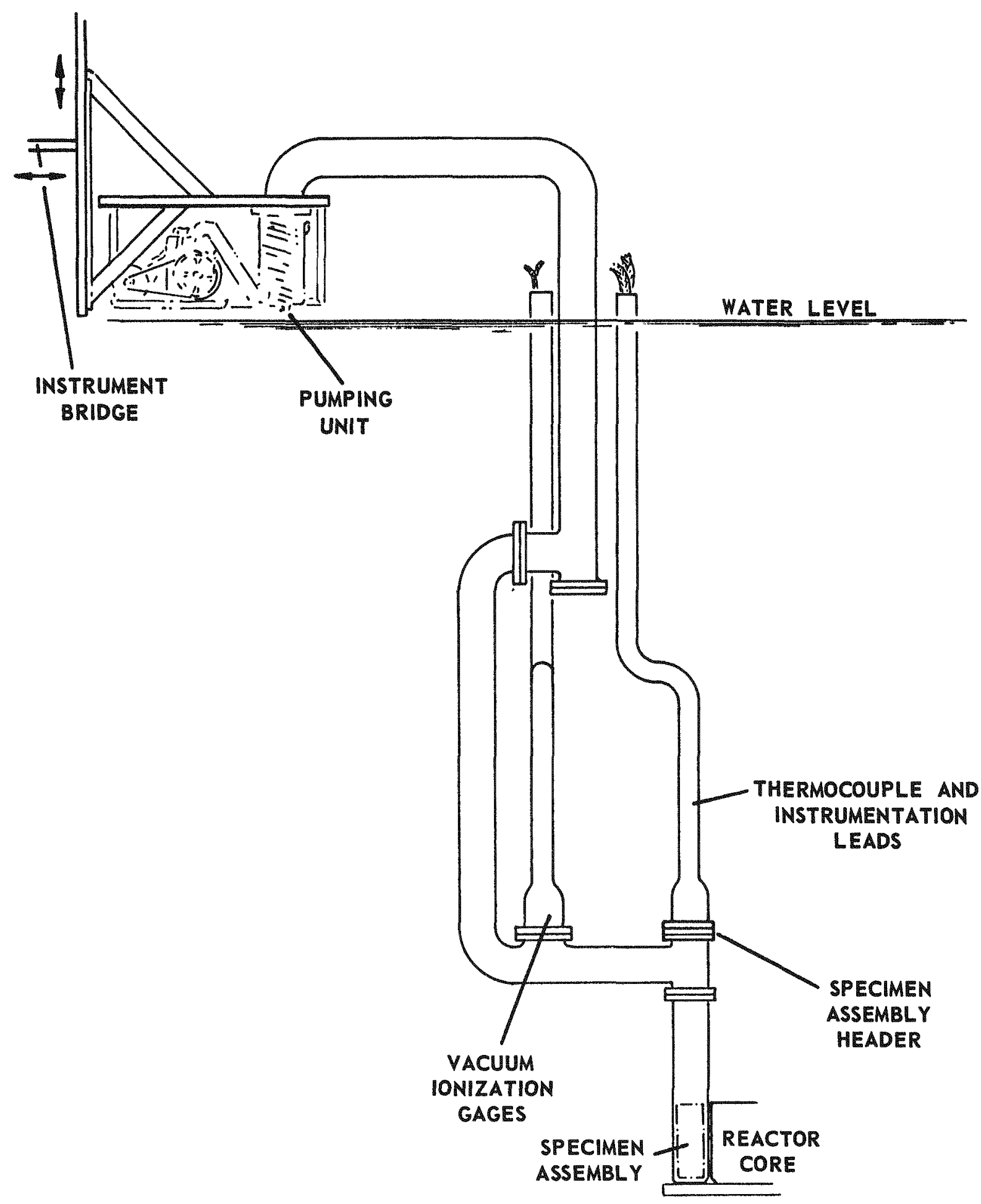

FIGURE 1. VACUUM IRRADIATION FACILITY AT FRONT CORE FACE OF BRR 
view of the long duration of this experiment ( 16 weeks as opposed to 6 weeks for previous high-flux experiments), the duplicate gages were placed in the system as spares.

The seal plate on the top side of the tee served as the exit point for thermocouple and electrical leads from the vacuum chamber. The specimen subassembly was suspended from this plate. Thirteen hermetic seals, each containing nine glass-insulated pins, were used as feedthroughs for thermocouples and specimen leads. Each nine-pin seal was vacuum sealed to the plate by a small natural-rubber O-ring held down by a threaded brass bushing. The six sheathed heaters were brazed into separate seal plugs and each of the six plugs were secured under the same type of $O-r i n g-b u s h i n g$ arrangement. When the header and specimen assembly was installed in the test chamber, a secondary header seal was produced by pouring a $1 / 2$-in. thick layer of epoxy on the header. The vacuum closures at the water-exposed flanges on both ends of the teesection were formed by a natural-rubber O-ring backed up by a lead O-ring.

Thermocouple and heater leads were brought from connecting plugs above the header to the movable bridge where temperature-recording instruments and heater power-control transformers were located. The specimen measurement leads, also attached to connectors above the header, were brought to a pool side box and were extended beyond to an air-conditioned instrument room.

$\underline{\text { Specimen Assemblies }}$

Figure 2 is a drawing of the experiment subassembly and Figure 3 shows the experiment in various stages of assembly. The actuator as semblies were fastened together end-to-end in a stainless steel and nickel framework with the position sensor of the upper actuator at the top of the specimen array and the sensor for the lower unit at the bottom of the test chamber. The assembly was divided into six heated zones. Each zone was bounded top and bottom by nickel baffles (7-1/2 in. in diameter $\times 0.037$ in. thick); the baffles in each zone were spaced by three equally spaced posts to which the coiled heaters were secured. The baffle assemblies were bolted together rigidly and secured to the actuator framework. Cutouts were provided in the various compartment baffles to allow them to be positioned around the actuator assembly and to provide for the passage of leads to the top of the test chamber. The magnetic pickups on each actuator were located in unheated areas.

Data measurement and thermocouple leads were mechanically attached to the vacuum side of the hermetic seals. All leads to the specimens were contained in eight multiwire cables which terminated in connectors attached to the various elements of the actuator assemblies. Short lengths of nickel wire were used to bridge the cabling to the leadout pins. The bare Chromel-Alumel thermocouple wires were tack welded at 34 locations throughout the assembly. All bare wires were insulated with ceramic tubing.

The 1/8-in.-diameter stainless steel-sheathed 2-kw heaters were wrapped around each zone as the last step before the insertion of the specimen assembly in the test section. The heaters were independently controlled and served effectively as secondary radiation baffles where the temperature variation was used to control compartment temperatures. 


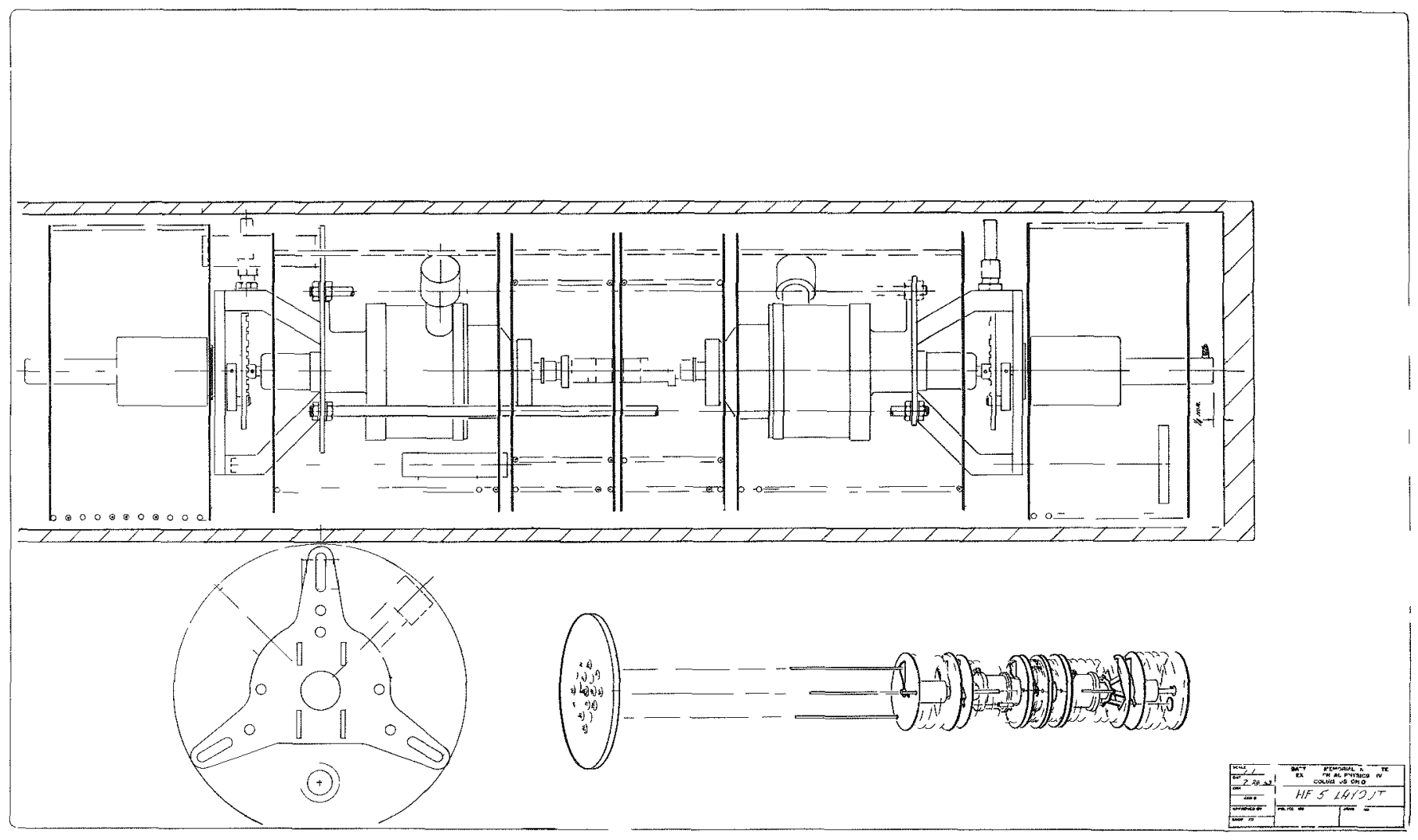

u

FIGURE 2. ASSEMBLY FOR HF- 5 EXPERIMENT 


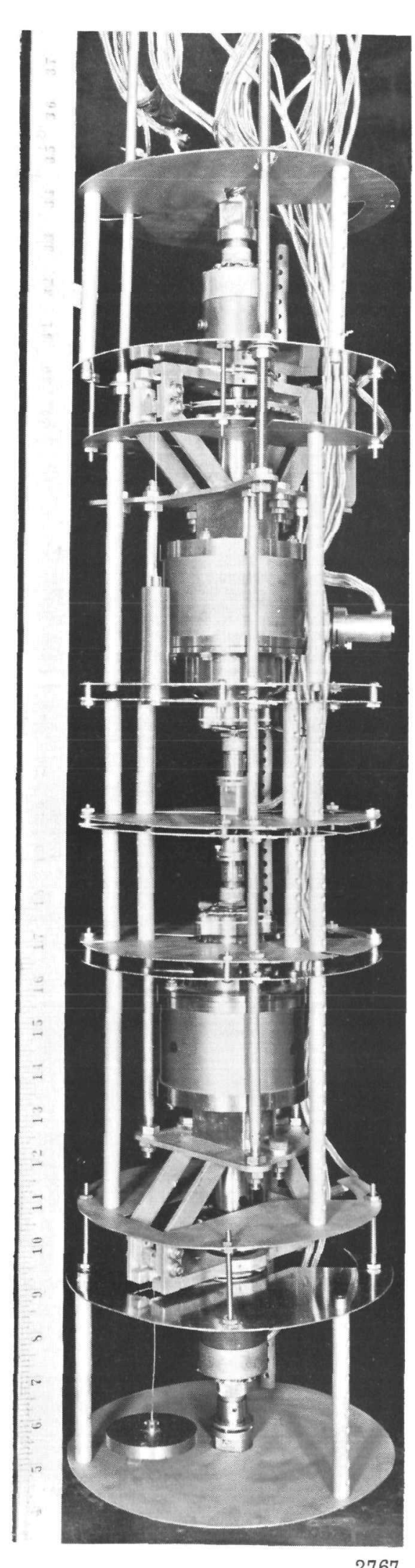

2767

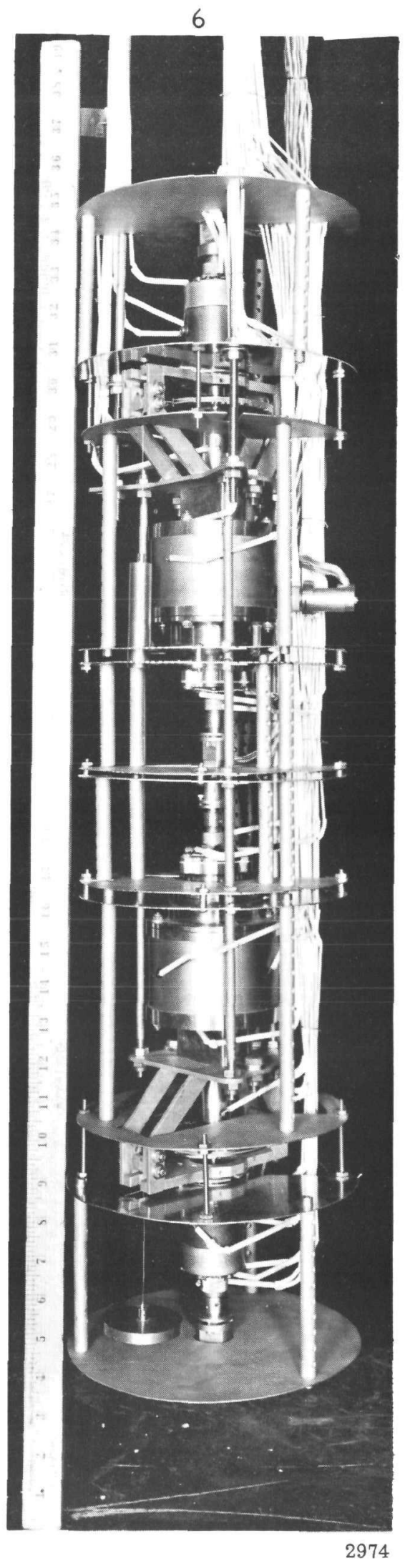

b. With Termocouple Leads

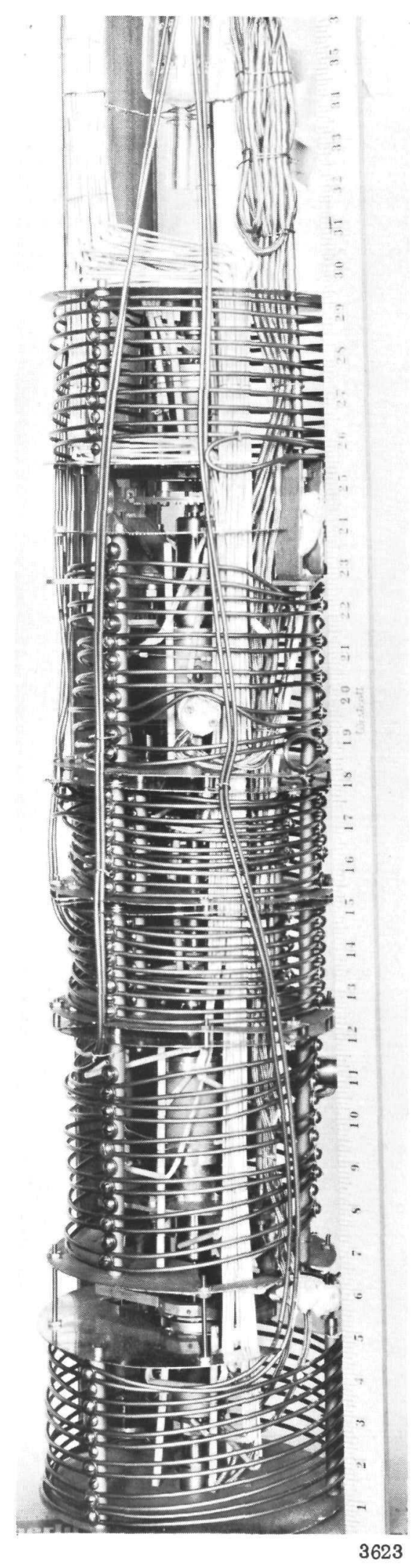

c. Final Assembly

a. With Measurement Leads 
TABLE 1. SUMMARY OF ACTUATOR HEAT-TRANSFER ANALYSIS

\begin{tabular}{|c|c|c|c|c|c|c|c|c|c|c|}
\hline \multirow{2}{*}{ Part Name } & \multirow{2}{*}{$\begin{array}{l}\text { Weight, } \\
\mathrm{g}\end{array}$} & \multicolumn{2}{|c|}{$\begin{array}{c}\text { Attenuation Factors, } \\
\text { Fraction of Incident } \\
\text { Radiation }\end{array}$} & \multirow[t]{2}{*}{$\begin{array}{c}\text { Maximum } \\
\text { Temperature, } \\
F\end{array}$} & \multirow[t]{2}{*}{$\begin{array}{l}\text { Temperature } \\
\text { Gradient, } \\
F\end{array}$} & \multirow[t]{2}{*}{$\begin{array}{l}\text { Heat } \\
\text { Generated, } \\
\text { Btu/hr }\end{array}$} & \multicolumn{4}{|c|}{ Heat Transferred, Btu $/ \mathrm{hr}$} \\
\hline & & External & Self-Shielding & & & & From & & TO & \\
\hline Magnet & 106 & 0.561 & 0.85 & 730 & -- & 1.45 & & & $\begin{array}{l}\text { Rotor }(C-R)(a) \\
\text { Central shaft }(R)\end{array}$ & $\begin{array}{l}1.30 \\
0.15\end{array}$ \\
\hline Rotor & 163 & 0.788 & 0.91 & 328 & -- & 3.31 & Magnet $(C-R)$ & 1.30 & $\begin{array}{l}\text { Central shaft }(C) \\
\text { Stator poles }(R) \\
\text { End bell front }(R) \\
\text { End bell rear }(R)\end{array}$ & $\begin{array}{l}0.32 \\
2.37 \\
0.96 \\
0.96\end{array}$ \\
\hline Central shaft & 18 & 0.415 & 0.87 ) & & & 0.19 & Magnet (R) & 0.15 & Brake drum (C) & 0.76 \\
\hline Brake end of shaft & 5 & 0.87 & $0.904\}$ & 728 & -- & 0.11 & Rotor (C) & 0.32 & Front end of shaft (C) & 0.34 \\
\hline Nuts and washers & 25 & 0.95 & $0.95 \mathrm{~J}$ & & & 0.65 & & & Inboard bearing $(R)$ & 0.32 \\
\hline Brake drum & 18 & 0.87 & 0.94 & 728 & $\infty$ & 0.42 & $\begin{array}{l}\text { Central shaft, etc. (C) } \\
\text { Armature (C) }\end{array}$ & $\begin{array}{l}0.76 \\
0\end{array}$ & $\begin{array}{l}\text { End bell rear (R) } \\
\text { End housing }(R)\end{array}$ & $\begin{array}{l}0.75 \\
0.47\end{array}$ \\
\hline $\begin{array}{l}\text { End bell rear } \\
\text { Inboard bearing }\end{array}$ & 99 & 0.90 & 0.939 & $\begin{array}{l}698 \\
706^{(b)}\end{array}$ & 8 & 2.39 & $\begin{array}{l}\text { Brake end of shaft (R) } \\
\text { Rotor (R) } \\
\text { Brake drum (R) }\end{array}$ & $\begin{array}{l}0.32 \\
0.96 \\
0\end{array}$ & $\begin{array}{l}\text { End housing (C) } \\
\text { Environment (R) } \\
\text { Stator case (C) }\end{array}$ & $\begin{array}{l}2.80 \\
1.23 \\
0\end{array}$ \\
\hline Armature & 36 & 0.88 & 0.96 & 728 & $+\infty$ & 0.87 & -- & - & $\begin{array}{l}\text { Brake housing }(R) \\
\text { Flexure (C) } \\
\text { Brake drum (C) }\end{array}$ & $\begin{array}{l}0.74 \\
0.16 \\
0\end{array}$ \\
\hline Flexure & 20 & 0.96 & 0.98 & 722 & -- & 0.54 & Armature (C) & 0.16 & End housing (R) & 0.70 \\
\hline Brake housing & 44 & 0.92 & 0.938 & 700 & $\approx 2$ & 1.09 & $\begin{array}{l}\text { Armature (R) } \\
\text { Brake coil (C) } \\
\text { Spring (R) }\end{array}$ & $\begin{array}{l}0.74 \\
0.37 \\
0.23\end{array}$ & Spring end cap (C) & 2. 27 \\
\hline Brake coil & 15 & 0.91 & 0.943 & 700 & -- & 0.37 & - & - & Brake housing (C) & 0.37 \\
\hline Spring & 17 & 0.94 & 0.92 & 701 & -- & 0.45 & $\cdots$ & -- & $\begin{array}{l}\text { End housing (R) } \\
\text { Brake Housing (R) }\end{array}$ & $\begin{array}{l}0.23 \\
0.23\end{array}$ \\
\hline Spring end cap & 25 & 1.00 & 0.928 & 691 & $\approx 2$ & 0.66 & $\begin{array}{l}\text { Brake housing (C) } \\
\text { End housing (C) }\end{array}$ & $\begin{array}{l}2.27 \\
1.75\end{array}$ & Environment (R) & 5. 19 \\
\hline End housing & 121 & 1.00 & 0.947 & 698 & -- & 3.27 & $\begin{array}{l}\text { Brake drum (R) } \\
\text { End bell rear (C) } \\
\text { Flexure (R) } \\
\text { Spring (R) }\end{array}$ & $\begin{array}{l}0.47 \\
2.80 \\
0.70 \\
0.23\end{array}$ & $\begin{array}{l}\text { Environment (R) } \\
\text { Spring end cap (C) }\end{array}$ & $\begin{array}{l}6.07 \\
1.75\end{array}$ \\
\hline Stator poles & 368 & 0.90 & 0.864 & 700 & 1 & 8. 15 & $\begin{array}{l}\text { Rotor }(R) \\
\text { Stator coil and } \\
\text { 1nsulation (C) }\end{array}$ & $\begin{array}{l}2.37 \\
1.71\end{array}$ & Stator case (C) & 11.56 \\
\hline $\begin{array}{l}\text { Stator coil and } \\
\text { insulation }\end{array}$ & 231 & 0.90 & 0.857 & 700 & 1 & 5.12 & $-\cdots$ & -- & $\begin{array}{l}\text { Stator case (C) } \\
\text { Stator poles (C) }\end{array}$ & $\begin{array}{l}3.41 \\
1.71\end{array}$ \\
\hline Stator case & 216 & 1.00 & 0.95 & 699 & -- & 5.88 & $\begin{array}{l}\text { Stator poles (C) } \\
\text { Stator coil (C) } \\
\text { End bell rear (C) }\end{array}$ & $\begin{array}{l}11.56 \\
3.41 \\
0\end{array}$ & $\begin{array}{l}\text { Environment (R) } \\
\text { End bell front (C) }\end{array}$ & $\begin{array}{r}20.08 \\
0.75\end{array}$ \\
\hline Front end of shaft & 39 & 0.956 & 0.889 & $\begin{array}{l}728 \\
722(c)\end{array}$ & 6 & 0.63 & Central shaft (C) & 0.34 & $\begin{array}{l}\text { End bell front (R) } \\
\text { and bearing }\end{array}$ & 0.97 \\
\hline $\begin{array}{l}\text { End bell front } \\
\text { and bearing }\end{array}$ & 181 & 1.00 & 0.941 & 698 & -- & 5.15 & $\begin{array}{l}\text { Rotor }(R) \\
\text { Stator case }(G) \\
\text { Front end of shat }(R)\end{array}$ & $\begin{array}{l}0.96 \\
0.75 \\
0.97\end{array}$ & Environment (R) & 7. 70 \\
\hline
\end{tabular}

(a) (C) denotes heat transferred by contact conductance.

(R) denotes heat transferred by radiation.

(b) Temperature of inboard bearing.

(c) Temperature of shaft at the outboard bearing. 
TABLE 2. INPUT FOR ACTUA TOR HEAT - TRANSFER ANALYSIS

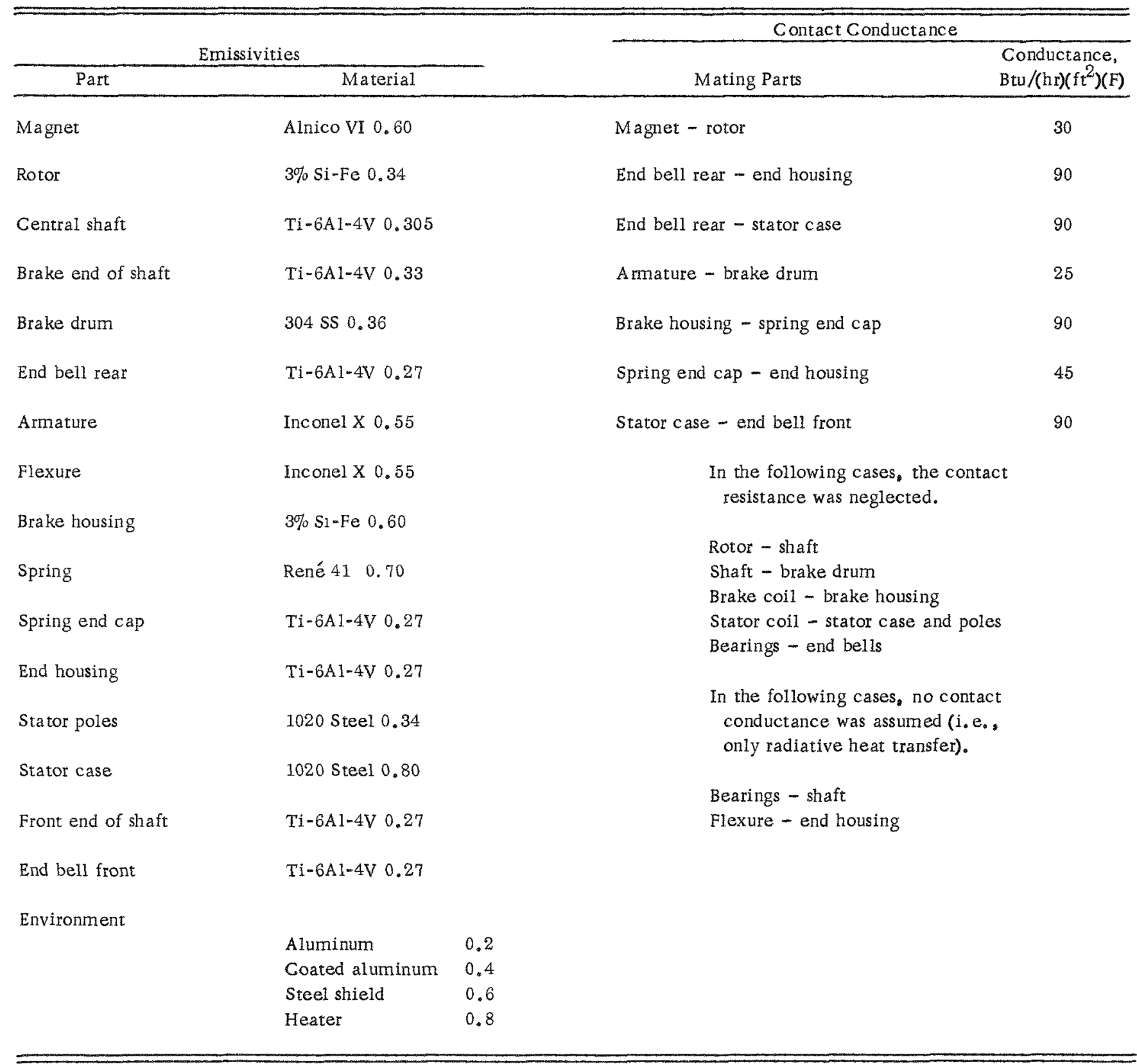


Heat-Transfer Considerations

Heat-transfer calculations were made to analyze the internal temperature distribution in the stepping motor, assuming a gamma exposure of $1.76 \times 10^{6} \mathrm{R} / \mathrm{hr}$ with the actuator stator and brake coils controlled at $700 \mathrm{~F}$. The analytical approach used was basically one dimensional with the geometry broken up into a series of slabs, cylindrical shells, and coils. This approach seemed adequate considering the uncertainties that existed in emissivity and contact-conductance values in a vacuum. Conservative values were used in carrying out the solution. The calculations were made as suming that the inside of the aluminum test sections would be flame sprayed with an alumina coating.

The summary of the solution for the actuator is presented in Table 1. Table 2 shows the inputs used in the analysis. The analysis indicated that radiation cooling was adequate for the entire assembly. The temperature gradients between the front and rear bearing and the shaft were $24 \mathrm{~F}$ and $22 \mathrm{~F}$, respectively. The temperature difference between the rotor and stator was $28 \mathrm{~F}$. These calculations offered assurance that difficulties resulting from temperature differences would not affect the operation of the actuator at temperature.

\section{FLUX-LEVEL CONSIDERA TIONS AND MEASUREMENTS}

\section{Background}

The nuclear environment achieved in this experiment was the result of the following factors:

(1) Atomics International's request that the neutron and gamma exposures received by the specimens adhere as closely as practicable to the specifications presented in Table 3

(2) The use of a BRR irradiation facility capable of accommodating the large test chamber needed to house the specimens, and its associated shielding

(3) An irradiation period of eight normal reactor cycles. A BRR cycle consists of a 14-day period, including 12 consecutive days spent at the full reactor power of $2 \mathrm{Mw}$.

TABLE 3. RADIA TION EXPOSURES SPECIFIED FOR THE HF - 5 EXPERIMENT

\begin{tabular}{lr}
\hline Neutron Energy & \multicolumn{1}{c}{ Specified Exposure } \\
\hline$>0.1 \mathrm{Mev}$ & $4.06 \times 10^{18} \mathrm{n} / \mathrm{cm}^{2}$ \\
$0.4 \mathrm{ev}-0.1 \mathrm{Mev}$ & $4.06 \times 10^{18} \mathrm{n} / \mathrm{cm}^{2}$ \\
$<0.4 \mathrm{ev}$ & $8.13 \times 10^{17} \mathrm{n} / \mathrm{cm}^{2}$ \\
Gamma Exposure & $4.06 \times 10^{9} \mathrm{R}$ \\
\hline
\end{tabular}


No problems were anticipated in attaining the flux levels requested for either fast or thermal neutrons, while the resonance-neutron flux available was uncertain. The large requested ratio of fast neutron-to-gamma exposure rates indicated the need for a lead shield to reduce the gamma exposure rate.

The investigation of radiation levels for the experiment involved nuclear measurements in an empty mock-up of the irradiation capsule, in a mock-up capsule containing an actuator assembly, and in the final test-specimen assembly. The measurements were conducted in three segments as outlined.

(1) Neutron and gamma fields were checked in the mock-up to aid in the decision of final experiment position and shielding

(2) Detailed mock-up measurements were made to determine neutron energy spectra and variations of the magnitudes of neutron fluxes and gamma exposure rates throughout the volume to be occupied by the test-specimen assemblies.

(3) Postirradiation analyses of several types of in-pile radiation detectors were conducted to determine the exposures actually received by the test specimens.

\section{Dosimetry Techniques Used in Mock-Up Measurements}

The mock-up facility was fabricated from a section of 8 -in. ID Schedule 40 aluminum pipe, 36 in. long. The bottom was sealed with a $0.50-$ in. plate and the top was fitted with a removable cap and special leadout tube for inserting dosimeters which were held within the chamber by special holders. Mock-up runs were conducted at reactor power levels ranging from $20 \mathrm{kw}$ to $1 \mathrm{Mw}$, depending on the activation characteristics of the detectors employed. Extrapolation to the full reactor power of $2 \mathrm{Mw}$ was made by using information gathered from several reactor-power monitors.

Initial checks of the neutron fluxes and gamma exposure rate in the mock-up capsule determined the position of the experiment relative to the reactor core, as well as the design of the gamma shield, as shown in Figure 4. The half-cylindrical lead shield was $1.62 \mathrm{in.} \mathrm{thick} \mathrm{and} \mathrm{was} \mathrm{high} \mathrm{enough} \mathrm{with} \mathrm{respect} \mathrm{to} \mathrm{the} \mathrm{BRR} \mathrm{core} \mathrm{to} \mathrm{shield} \mathrm{the} \mathrm{region}$ occupied by the test actuator assemblies. A concentric half-cylinder of 0.25 -in. -thick Boral was fitted around the lead shield to reduce the thermal neutron flux incident upon the lead and thereby reduce the number of neutron-capture reactions in the lead. This produced a 60 per cent reduction in the gamma observed in the test capsule. A water leak was detected in the cladding of the first Boral shield during the operation of the experiment, necessitating its replacement by an essentially identical one. 


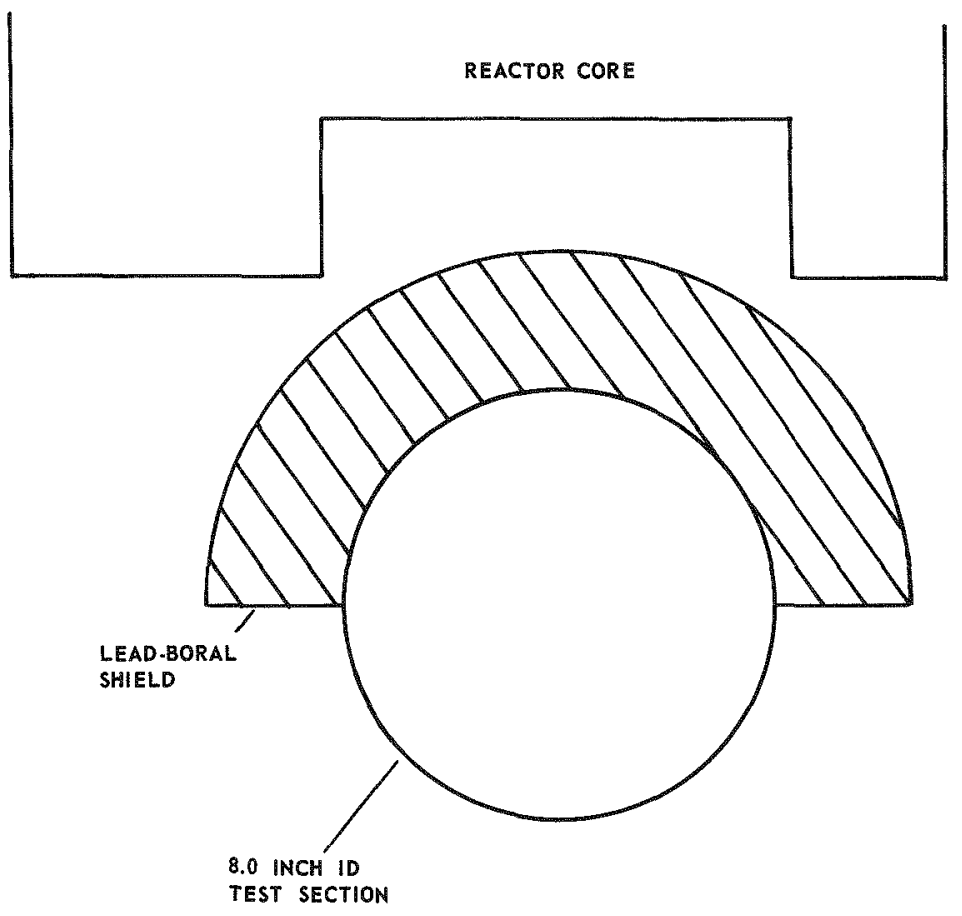

FIGURE 4. LOCATION OF HF-5 TEST SECTION AND SHIELD WITH RESPECT TO THE BRR CORE

Initial thermal-neutron measurements indicated the need for a cadmium sleeve about 6 mils thick to surround the test section for reduction of the thermal neutron flux. However, the Boral shield used to reduce capture gammas also served this purpose, and the cadmium was omitted from the final system design.

The detailed mock-up dosimetry consisted of both neutron and gamma investigations. Included were measurements of neutron energy spectra, neutron flux distributions, and the gamma-exposure-rate distribution. The analysis of the incident neutron field was based on the division of the neutrons into three energy groups and the use of measurement techniques applicable to the three groups. The three groups are defined as follows:

(1) Fast neutrons - neutrons with energies greater than 0. $1 \mathrm{Mev}$.

(2) Resonance neutrons - neutrons with energies between about $0.4 \mathrm{ev}$ and $0.1 \mathrm{Mev}$.

(3) Thermal neutrons - neutrons with energies less than about $0.4 \mathrm{ev}$.

The techniques and experimental procedures used to measure the neutron energy spectra, neutron flux distributions, and the gamma-exposure-rate distribution follow. Data obtained in these measurements are presented in later sections. 


\section{Neutron Energy Spectra}

To obtain a representation of the spectrum in the fast-neutron energy range, integral fluxes were measured by a set of detectors whose reaction cross-section values approximate step increases at threshold energies spanning a range of about $6 \mathrm{Mev}$. The reactions used were $\mathrm{Pu}^{239}(\mathrm{n}, \mathrm{f}), \mathrm{U}^{238}(\mathrm{n}, \mathrm{f}), \operatorname{In}^{115}\left(\mathrm{n}, \mathrm{n}^{\mathrm{i}}\right), \mathrm{Ni}^{58}(\mathrm{n}, \mathrm{p}), \mathrm{S}^{32}(\mathrm{n}, \mathrm{p}), A \mathrm{I}^{27}(\mathrm{n}, \mathrm{p})$, $\mathrm{Fe}^{54}(\mathrm{n}, \mathrm{p}) \mathrm{Mg}^{24}(\mathrm{n}, \mathrm{p})$, and $\mathrm{Al} 27(\mathrm{n}, \alpha)$.

Plutonium measures the integral neutron flux above $4 \mathrm{kev}$. To approximate the integral fast neutron flux, the integral flux between $4 \mathrm{kev}$ and $100 \mathrm{kev}$ was subtracted from the plutonium flux. This correction was based on the resonance neutron flux measured in the mock-up at the location of the plutonium detector.

The data were compared with an analytic function representing a hydrogenmoderated fission spectrum further modified by inelastic neutron scattering in the lead gamma shield.

To obtain a representation of the spectrum in the resonance-neutron energy range, differential neutron fluxes were measured by the cadmium-difference method, which assumes that a valid representation of the differential neutron flux between energies $E$ and $E+d E$ is given by the expression:

$$
\phi(E) \mathrm{dE}=\frac{\phi_{0}}{\mathrm{E}} \mathrm{dE}
$$

The spectral function parameter, $\phi_{0}$, is given by*

$$
\phi_{0}=\frac{2.27 \phi \text { th }}{(\mathrm{CR}-1)(1+\alpha)}
$$

where

$$
\begin{aligned}
\phi t h= & \text { thermal neutron flux } \\
C R= & \text { cadmium ratio } \\
\alpha= & \text { a number characteristic of the resonance cross section } \\
& \text { of the detector used. }
\end{aligned}
$$

The factor 2.27 includes the effect of the cadmium-cover thickness.

The assumption that the cadmium-difference method was valid, that is, that the resonance energy spectrum was proportional to the reciprocal neutron energy was established by comparing the values of $\phi_{0}$ for several resonance detectors as calculated from their cadmium ratios measured in the mock-up.

The reactions used for measuring the differential spectrum in the resonance energy region were $\mathrm{Co}^{59}(\mathrm{n}, \gamma), \mathrm{Cu}^{63}(\mathrm{n}, \gamma), \mathrm{V}^{51}(\mathrm{n}, \gamma)$, and $\mathrm{Al}^{27}(\mathrm{n}, \gamma)$.

\footnotetext{
"Tentative Recommended Practice for Measuring Neutron Flux Environment for Reactor Irradiated Specimens", ASTM E 199$62 \mathrm{~T}$.
} 
Neutron-Flux Distributions

The neutron-flux distributions were measured by dispersing appropriate detectors throughout the volume of the mock-up. Fast-neutron-detector foils permitted threshold flux values to be determined at 85 points within the mock-up. These values were then converted to total fast-neutron-flux values using the analytic fast-neutron spectrum measured in the mock-up, as described above.

Resonance-neutron-detector foils irradiated with and without cadmium covers permitted the use of the validated cadmium-difference method to calculate the spectral function parameter, $\phi_{O}$, at 30 points within the mock-up. With the calculated values of $\phi_{0}$, the resonance-neutron-flux distribution can be determined.

Neutron-detector foils with and without 20- to 40-mil-thick cadmium covers were used to measure the thermal neutron flux at 30 points within the mock-up. The difference in the responses of the bare and cadmium-covered detectors is proportional to the thermal neutron flux.

Gamma-Exposure-Rate Distribution

Gamma exposure rates were measured in the mock-up by $10-\mathrm{cm}^{3}$ graphite-walled ionization chambers. A small flow of carbon dioxide at atmospheric pressure was maintained through each chamber. A regulated power supply operated the chambers at $500 \mathrm{v}$; output currents were measured by a Keithley Model 414 micromicroammeter.

Prior to the measurements, the chambers were calibrated against copper-modified ferrous sulfate chemical dosimeters at the Battelle Cobalt-60 Irradiation Laboratory. In-pile exposure-rate measurements were corrected for the presence of fast neutrons. This correction is approximately $9.3 \times 10^{-5} \mathrm{erg} /(\mathrm{g})(\mathrm{hr})(\mathrm{carbon})$ per $\mathrm{n} /\left(\mathrm{cm}^{2}\right)(\mathrm{sec})$.

\section{Results of Mock-Up Operations}

This section presents the mock-up results acquired by the techniques and procedures described previously.

Neutron Energy Spectra

All spectral measurements were made at a point on the axis of the mock-up 11 in. above the bottom of the test region.

The integral fast neutron spectrum is shown in Figure 5 . The integral flux above $0.1 \mathrm{Mev}$ was $7.8 \times 10^{11} \mathrm{n} /\left(\mathrm{cm}^{2}\right)(\mathrm{sec})$. This spectrum was used to interpret subsequent fast neutron fluxes measured by one or more of the listed threshold reactions in both mock-up and in-pile irradiations. 


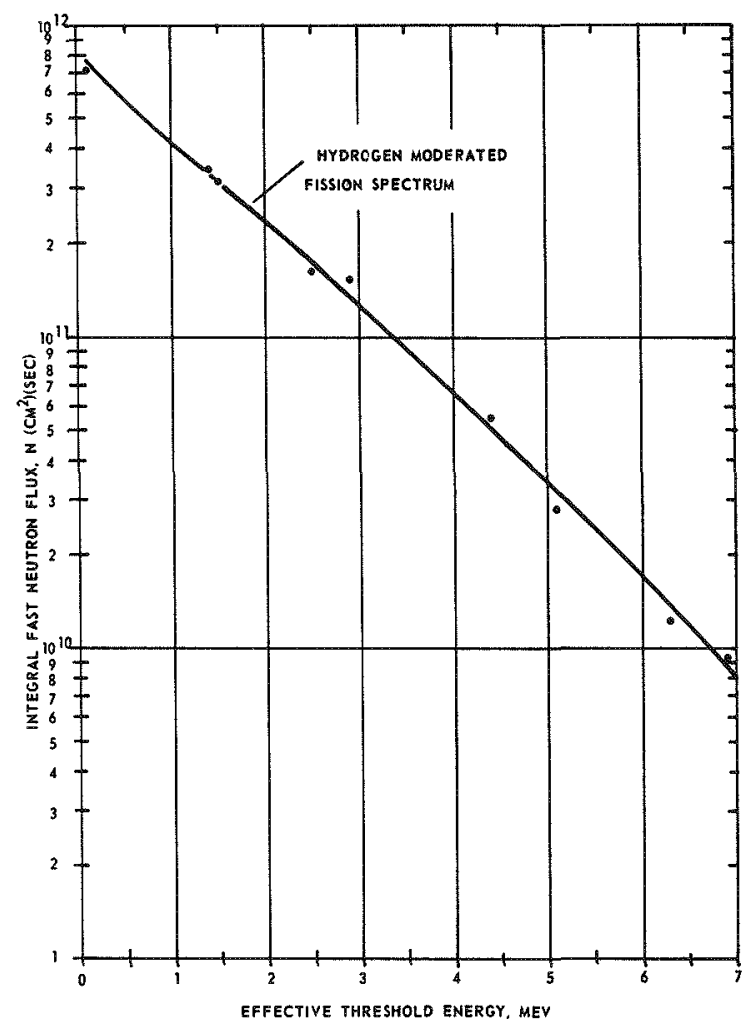

FIGURE 5. FAST NEUTRON SPECTRUM IN HF-5 MOCK-UP EXPERIMENT

The differential resonance neutron spectrum is shown in Figure 6. The validity of the assumption that the resonance energy spectrum is proportional to the reciprocal energy was confirmed over the measured energy interval. The value of the spectral function parameter, $\phi_{0}$, for the four detectors was $4.8 \times 10^{10} \mathrm{n} /\left(\mathrm{cm}^{2}\right)(\mathrm{sec})$ with a deviation of \pm 20 per cent.

\section{Neutron-Flux Distributions}

All distribution measurements were made at the same five radial positions in the mock-up - one at the center along the mock-up axis and four at 90-degree intervals around the periphery of the test region. Fast-neutron measurements were made over a 28-in. axial span using nickel dosimeter wires. Resonance- and thermal-neutron measurements were made over a 20-in. axial span using cobalt-foil dosimeters with and without 20 to $40-$ mil-thick cadmium covers.

The volume-averaged values of fast and thermal neutron fluxes, and of the resonance neutron flux and $\phi_{0}$, are listed in Table 4. Also listed are the maximum axial and radial variations in the measured values. For each set of neutron-flux distribution measurements, the flux values at the five radial positions were averaged at various axial positions. Figure 7 indicates the average radial fluxes as functions of axial position. 


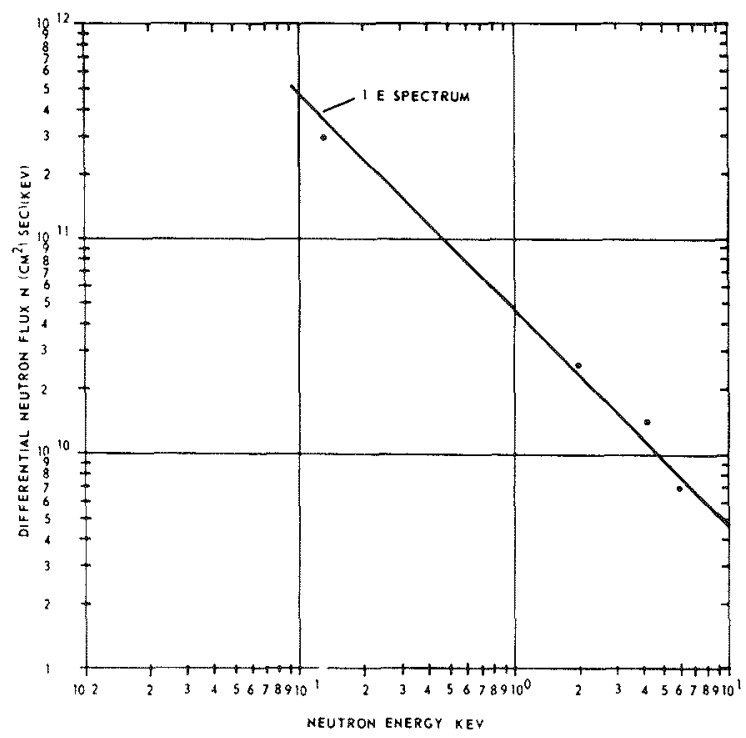

FIGURE 6. RESONANCE NEUTRON SPECTRUM IN HF-5 MOCK-UP EXPERIMENT

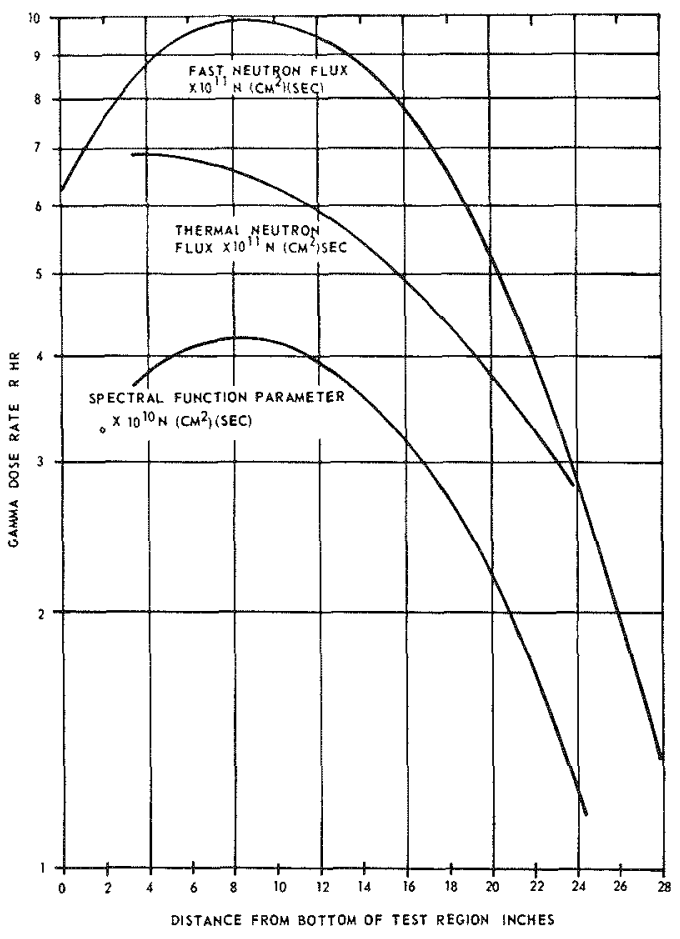

FIGURE 7. NEUTRON-FLUX DISTRIBUTIONS IN HF-5 MOCK-UP EXPERIMENTS 
TABLE 4. NEUTRON FLUXES MEASURED IN MOCK-UP

\begin{tabular}{lccc}
\hline \multicolumn{1}{c}{ Description } & $\begin{array}{c}\text { Average Flux, } \\
\mathrm{n} /\left(\mathrm{cm}^{2}\right)(\mathrm{sec})\end{array}$ & Maximum Variations \\
\hline Fast neutrons & $6.5 \times 10^{11}$ & 7.4 & Radial \\
Thermal neutrons & $5.2 \times 10^{11}$ & 2.5 & 2.0 \\
Parameter $\phi_{0}$ & $3.1 \times 10^{10}$ & 3.5 & 1.2 \\
Resonance neutrons & $3.8 \times 10^{11}$ & 3.5 & 1.6 \\
\end{tabular}

Gamma-Exposure-Rate Distribution

Gamma-distribution measurements were taken over a 26-in. axial span at five radial positions at the center and at 90-degree intervals around the periphery of the test region. The volume-averaged dose rate with the first lead-Boral shield was $2.5 \times 106$ $\mathrm{R} / \mathrm{hr}$. With the second shield, it was $1.6 \times 10^{6} \mathrm{R} / \mathrm{hr}$. The maximum axial and radial variations were 3.8 and 1.7 , respectively. Figure 8 indicates the average radial exposure rate as a function of axial position for the first shield.

Actuator Dosimetry

In-pile neutron exposures of internal parts of the two test actuators could not be measured directly during the irradiation. To determine these internal exposures, an identical actuator was disassembled and indium- and nickel-foil dosimeters were attached to the actuator at 25 points, both internal and external. The actuator was reassembled and irradiated under static conditions in the mock-up capsule.

At the position of each set of dosimeters, the ratio of indium-to-nickel threshold fluxes was determined and compared with the ratio observed in the unperturbed environment. The average difference was less than 1 per cent, indicating that the total fast neutron flux inside the actuators could be approximated well by use of threshold flux values and the fast-neutron energy spectrum measured previously.

The various dosimeter positions established correlations between internal and external neutron fluxes. These correlations were used to determine internal neutron exposures from the external exposures measured during the in-pile operation, when internal dosimeters could not be used.

\section{IN-PILE OPERATION}

The experiment was conducted in the vacuum facility located at the front core face of the BRR for a period of 16 weeks, eight reactor cycles. The total irradiation period was about 2183 hours. During the experiment, the operating-temperature levels and 


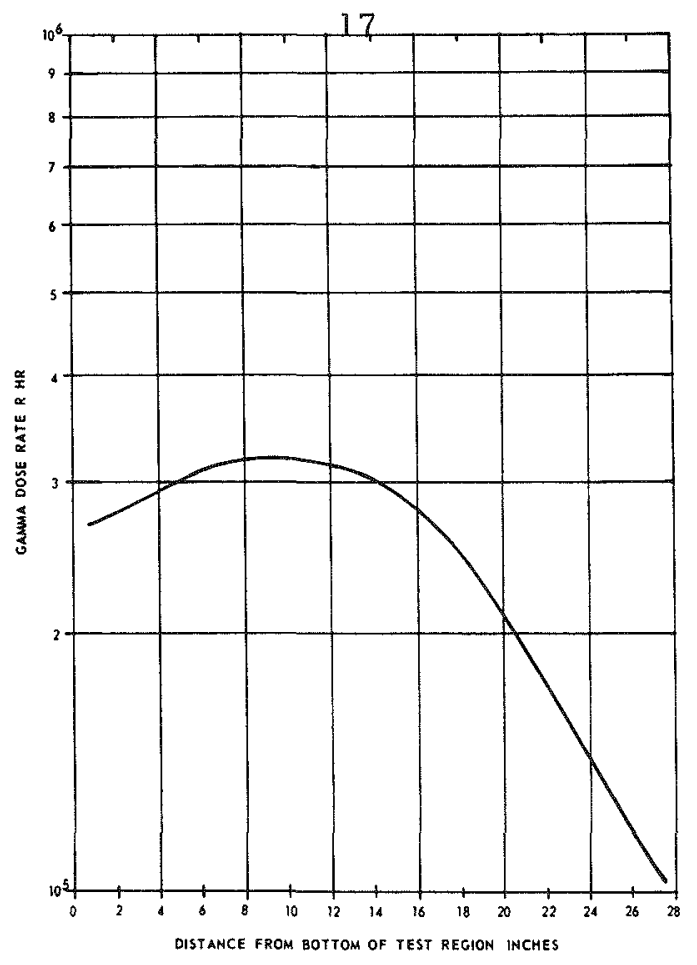

FIGURE 8. GAMMA DOSE RATE IN HF-5 MOCK-UP EXPERIMENT

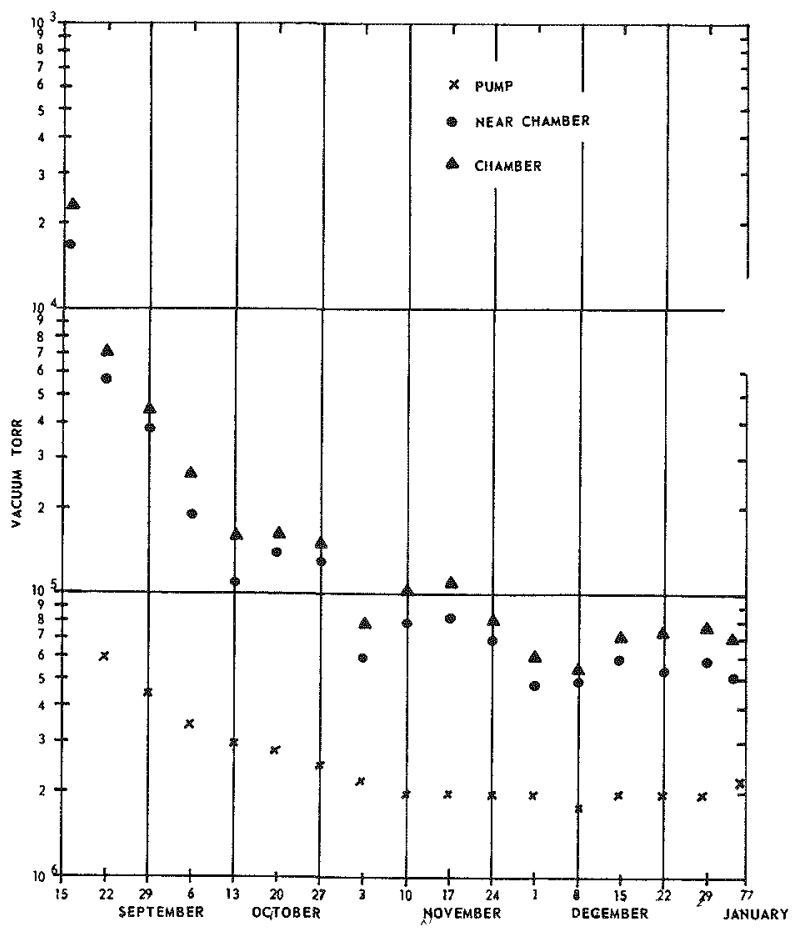

FIGURE 9. VACUUM LEVELS MONITORED DURING THE HF-5 EXPERIMENT 
system vacuum were maintained continuously, both for in-pile and out-of-pile periods. Measurements of selected specimen electrical characteristics and operation of the units were carried out periodically during the experiment.

System Vacuum

Vacuum levels monitored at three locations in the system are presented in Figure 9. The ionization gages were operated for short periods daily to sample system vacuum; this produced the noted scatter in the data.

Considerable liquid nitrogen was used during this experiment in part because of leaks in the supply system which could not be repaired during operation. Several times the liquid nitrogen supply was exhausted before the system was checked in the morning. However, only slight losses of vacuum were noted at these times.

The only major vacuum difficulties were encountered during the first cycle of irradiation. On the ninth irradiation day, a 30-min general power failure disrupted all reactor operations. When the power was restored, the forepump would not evacuate the system. Actuator temperatures were held below $300 \mathrm{~F}$ and system pressure increased to 0.3 torr before pumping was restored. Several days later the glass envelope of an ionization gage near the pump was accidently cracked near a pin. Heaters and pumps were turned off immediately and the crack was temporarily sealed until specimens were cooled sufficiently; system pressure increased to 0.8 torr. The gage was replaced and vacuum levels were restored to normal operating conditions. The operational periods with poor vacuum had no apparent effect on the operating characteristics of the actuators.

\section{Specimen Temperatures}

The specified operating temperatures for the assemblies were:

(1) $720 \mathrm{~F}$ for the coils of the actuator and the brake

(2) $520 \mathrm{~F}$ for the position sensor

(3) Less than $700 \mathrm{~F}$ for the magnetic pickups (not controlled).

These temperatures were calculated by using measurements of the resistance of the coils and data developed by Atomics International, presented in Figure 10, to obtain the coil temperatures, which could not be measured directly. These calculated temperatures were used as the basis for adjustment of the auxiliary heater controls. 


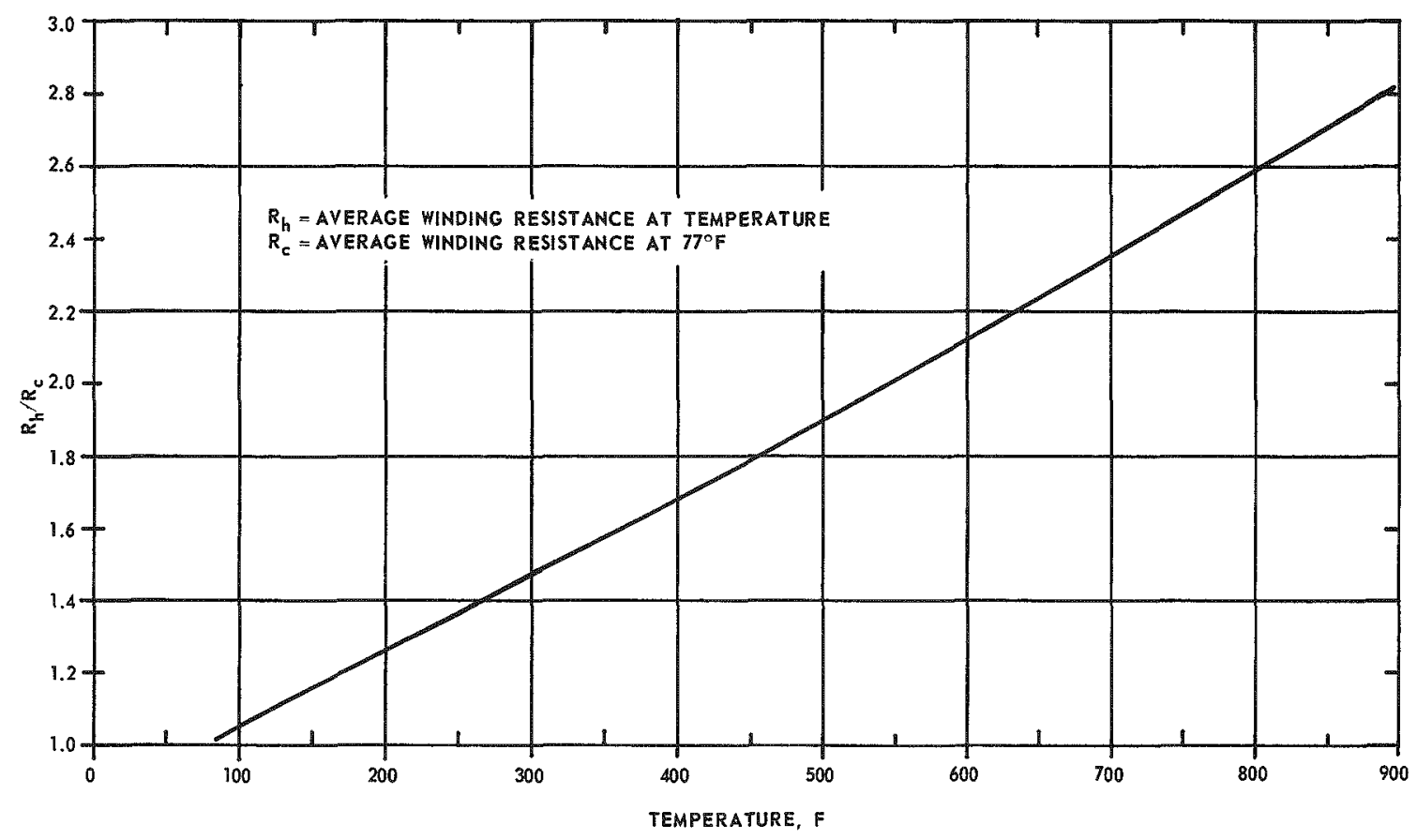

\section{FIGURE 10. TEMPERATURE AS A FUNCTION OF THE RA TIO OF AVERAGE WINDING RESISTANCE FOR COPPER WIRE}

The above procedure resulted in wide variations in the temperatures of the coils (as calculated). This can be seen in Figures 11 and 12 which show plots of these calculated temperatures. These variations were reflected in the measured temperatures of the outer shells of the parts as shown in Figures 15 and 16. The shell temperatures did not vary as much as the calculated values, however. Apparently a large thermal lag existed in the experimental assembly, and the changes in heater power control were not reflected immediately in the coil temperatures.

Accordingly, the procedures for heater power control were changed to take this lag into account. It was found that almost 24 hours was required for full the rmal equilibrium to be achieved after changes in heater power setting. This change in operational procedure resulted in much more uniform temperatures for the remaining six cycles of the experiment (see Figures 13 through 16). The temperature levels are summarized in Table 5. 


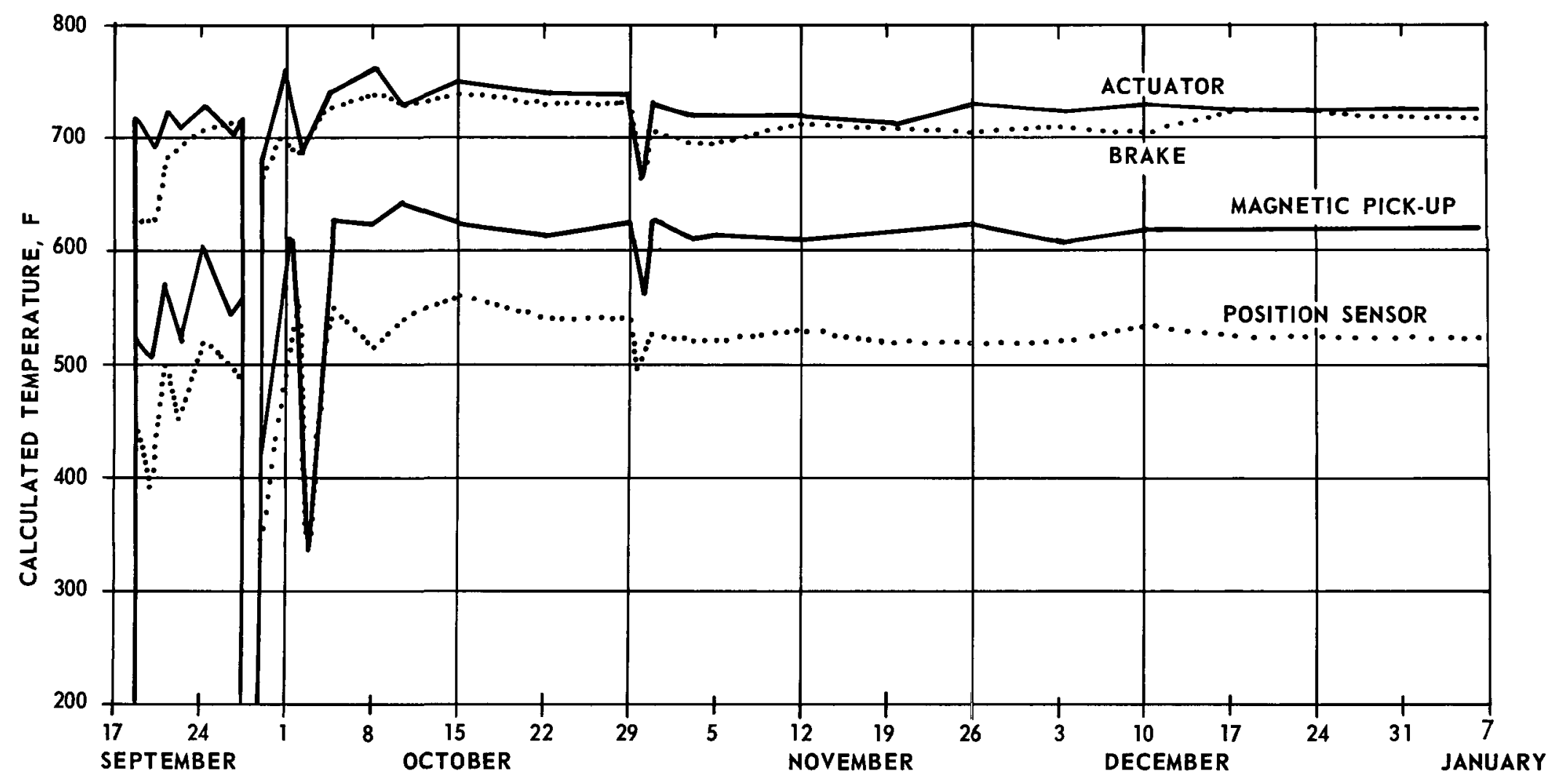

FIGURE 11. COIL TEMPERATURES AS DETERMINED BY COIL RESISTANCE MEASUREMENTS FOR THE UPPER ASSEMBLY IN HF-5 


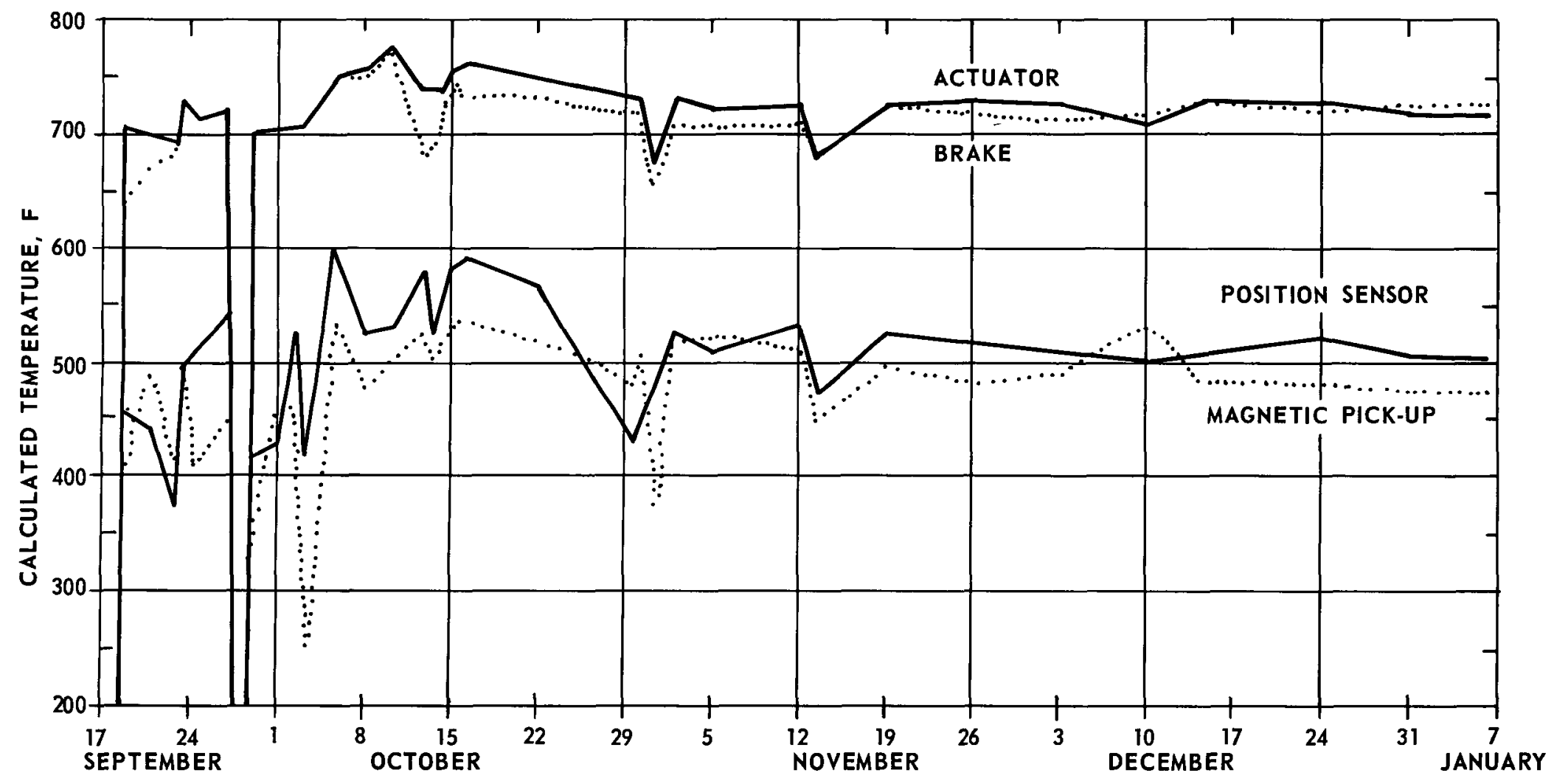

FIGURE 12. COIL TEMPERATURES AS DETERMINED BY COIL RESISTANCE MEASUREMENTS FOR THE LOWER ASSEMBLY IN HF-5 


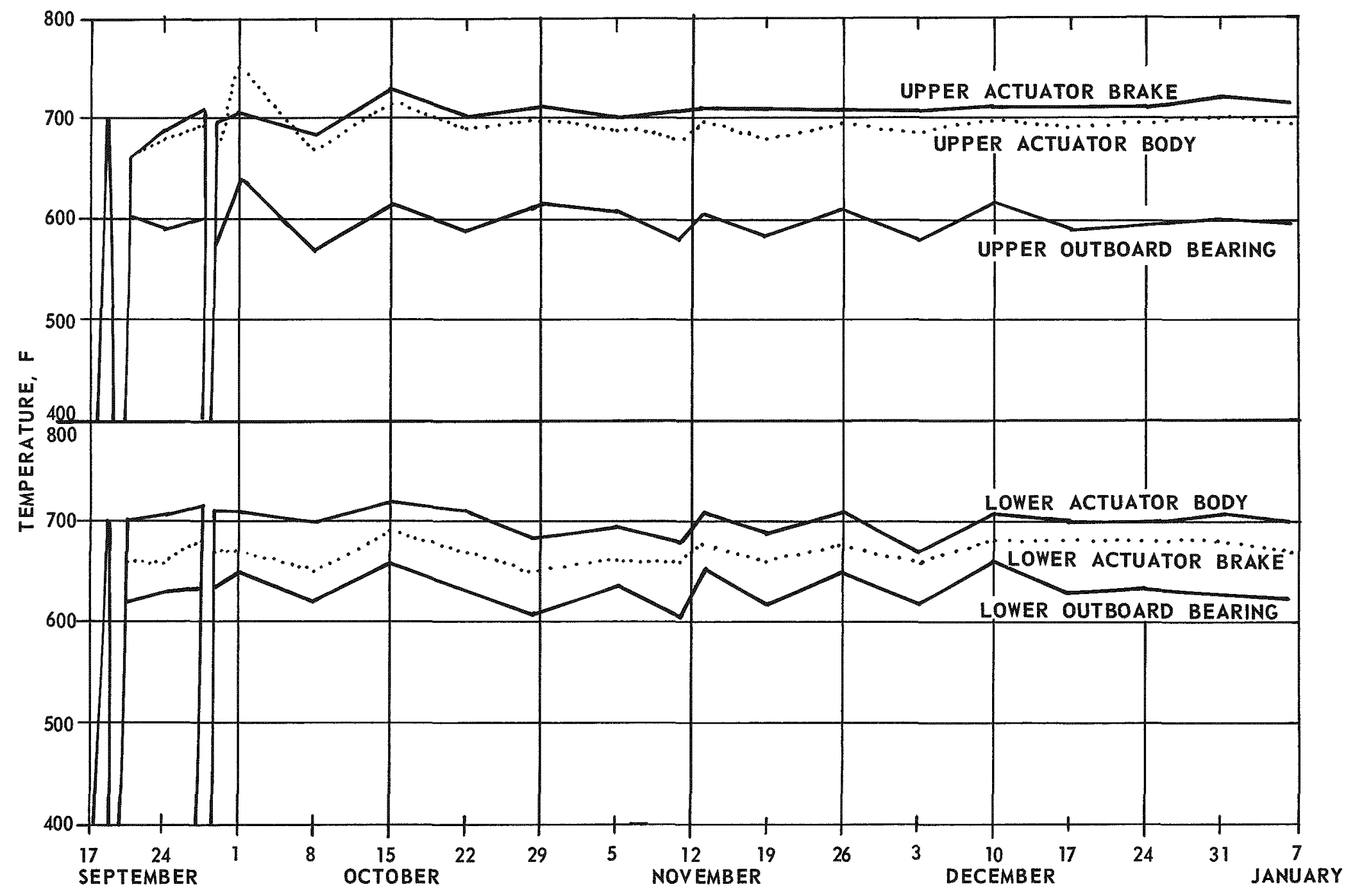

FIGURE 13. TEMPERATURE OF ACTUATOR BODIES AND BRAKE HOUSINGS IN THE HF-5 EXPERIMENT 


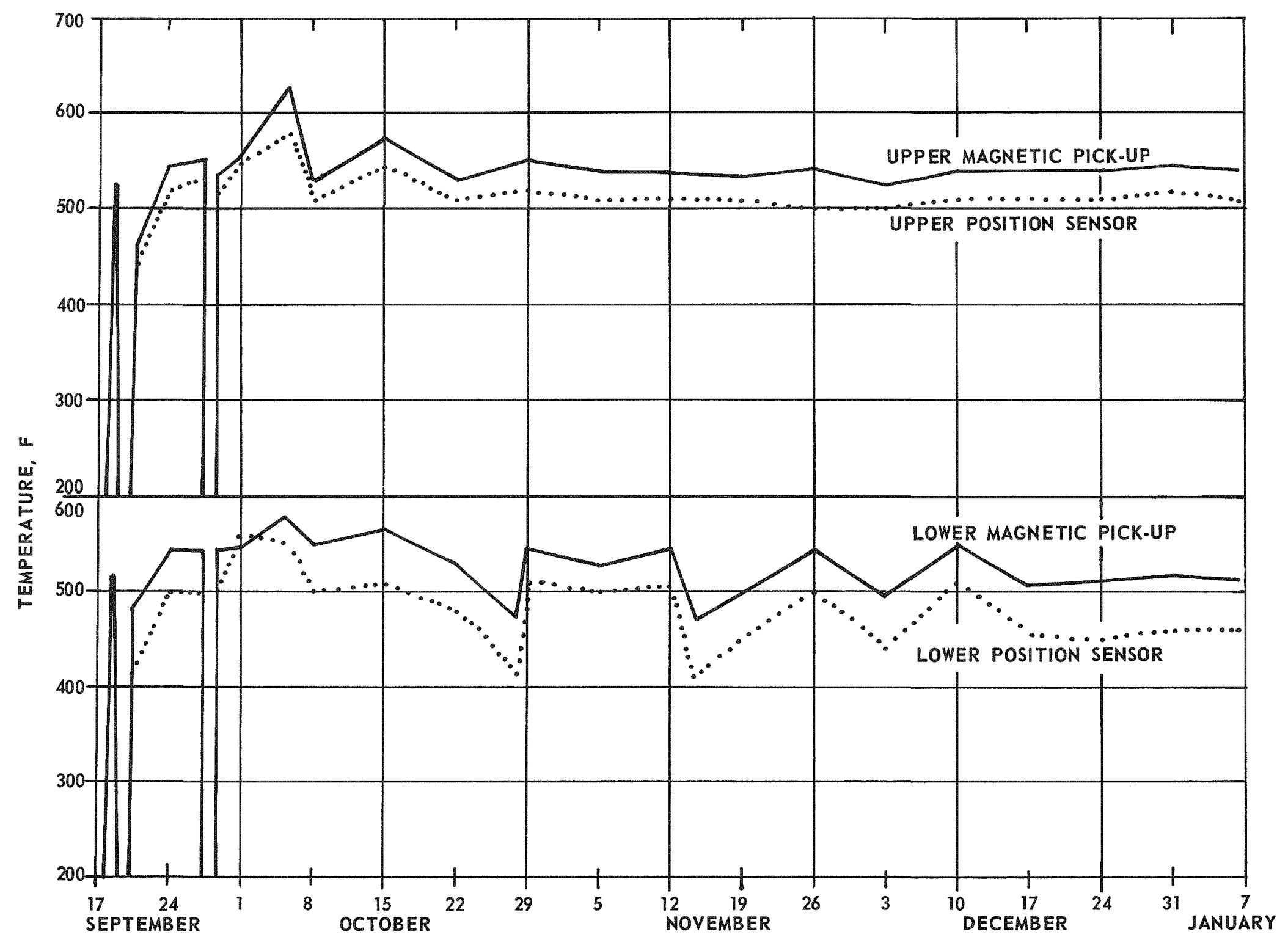

FIGURE 14. TEMPERATURES OF POSITION SENSORS AND MAGNETIC PICK-UPS IN HF- 5 EXPERIMENT 


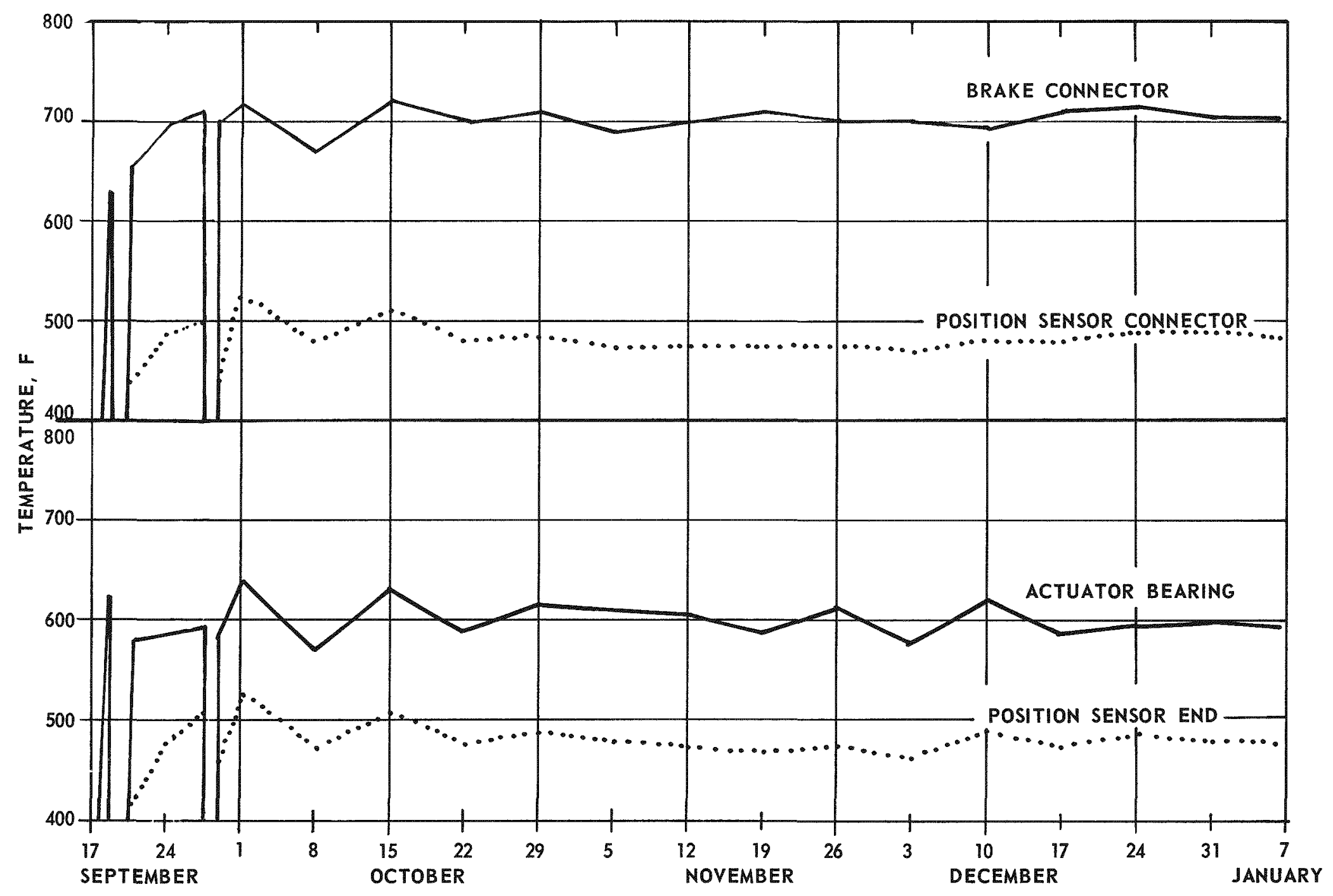

FIGURE 15. TEMPERATURE OF COMPONENTS IN UPPER ASSEMBLY OF HF-5 


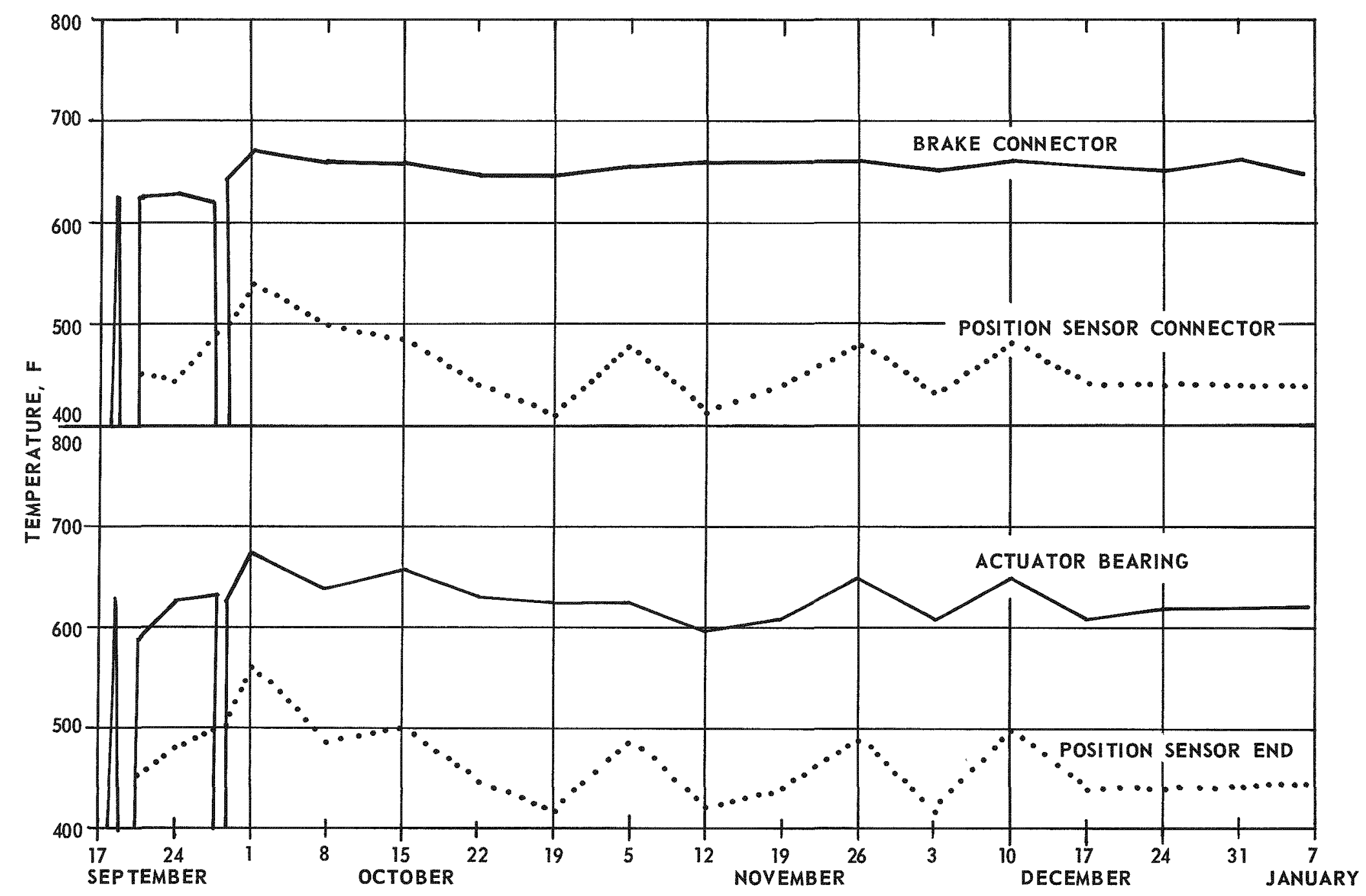

N

FIGURE 16. TEMPERATURE OF COMPONENTS IN THE LOWER ASSEMBLY OF HF-5 
TABLE 5. TEMPERATURE LEVELS OF MAJOR COMPONENTS DURING THE IRRADIA TION OF EXPERIMENT HF-5

\begin{tabular}{|c|c|c|c|c|}
\hline Subassembly Part & $\begin{array}{c}\text { Type of } \\
\text { Measurement }(a)\end{array}$ & $\frac{\text { Average }}{\text { Cycle } 140}$ & $\frac{\text { Temperatures }}{\text { Cycle } 141}$ & $\frac{\text { s and Limits, } F}{\text { Cycle } 142 \text { to } 147}$ \\
\hline \multicolumn{5}{|l|}{ Upper Actuator } \\
\hline Position sensor case & $\mathrm{TC}$ & $530 \pm 30$ & $550 \pm 30$ & $515 \pm 15$ \\
\hline Position sensor coil & CR & $460 \pm 70$ & $550 \pm 75$ & $525 \pm 25$ \\
\hline Magnetic pickup case & $\mathrm{TC}$ & $540 \pm 10$ & $560 \pm 30$ & $530 \pm 20$ \\
\hline Magnetic pickup coil & CR & $550 \pm 50$ & $620 \pm 40$ & $615 \pm 15$ \\
\hline Bearing & $\mathrm{TC}$ & $590 \pm 10$ & $600 \pm 25$ & $600 \pm 20$ \\
\hline Actuator case & TC & $690 \pm 10$ & $700 \pm 25$ & $690 \pm 15$ \\
\hline Actuator case & $\mathrm{CR}$ & $700 \pm 25$ & $715 \pm 35$ & $725 \pm 25$ \\
\hline Brake case & $\mathrm{TC}$ & $690 \pm 10$ & $700 \pm 25$ & $700 \pm 15$ \\
\hline Brake coil & CR & $710 \pm 30$ & $710 \pm 35$ & $715 \pm 20$ \\
\hline Connector & $\mathrm{TC}$ & $680 \pm 30$ & $710 \pm 30$ & $705 \pm 15$ \\
\hline \multicolumn{5}{|l|}{ Lower Actuator } \\
\hline Position sensor case & $\mathrm{TC}$ & $500 \pm 15$ & $525 \pm 40$ & $460 \pm 40$ \\
\hline Position sensor coil & $\mathrm{CR}$ & $500 \pm 50$ & $525 \pm 75$ & $515 \pm 20$ \\
\hline Magnetic pickup case & TC & $540 \pm 10$ & $550 \pm 30$ & $520 \pm 40$ \\
\hline Magnetic pickup coil & $\mathrm{CR}$ & $450 \pm 50$ & $475 \pm 50$ & $490 \pm 30$ \\
\hline Bearing & $\mathrm{TC}$ & $630 \pm 10$ & $640 \pm 25$ & $615 \pm 20$ \\
\hline Actuator case & TC & $690 \pm 10$ & $700 \pm 25$ & $680 \pm 30$ \\
\hline Actuator coil & $C R$ & $710 \pm 35$ & $725 \pm 25$ & $725 \pm 25$ \\
\hline Brake case & $\mathrm{TC}$ & $670 \pm 20$ & $660 \pm 20$ & $650 \pm 25$ \\
\hline Brake coil & $\mathrm{CR}$ & $710 \pm 35$ & $710 \pm 35$ & $715 \pm 20$ \\
\hline Connector & TC & $650 \pm 25$ & $650 \pm 20$ & $650 \pm 25$ \\
\hline
\end{tabular}

(a) TC - thermocouple, CR - coil resistance.

Specimen Performance Measurements

The following is a summary of the results of electrical measurements and operation during the irradiation of the actual assemblies. The results are presented without analysis or discussion and are not necessarily an indication of the true performance of the components.

Electrical Measurements

The electrical measurements were made using the four basic circuits shown in Figure 17.

Insulation Resistance. Insulation-resistance measurements were made with the power supply adjusted for a constant $50 \mathrm{v}$. The voltage drop across a precision shunt resistor was measured and the insulation resistance calculated. The insulation 

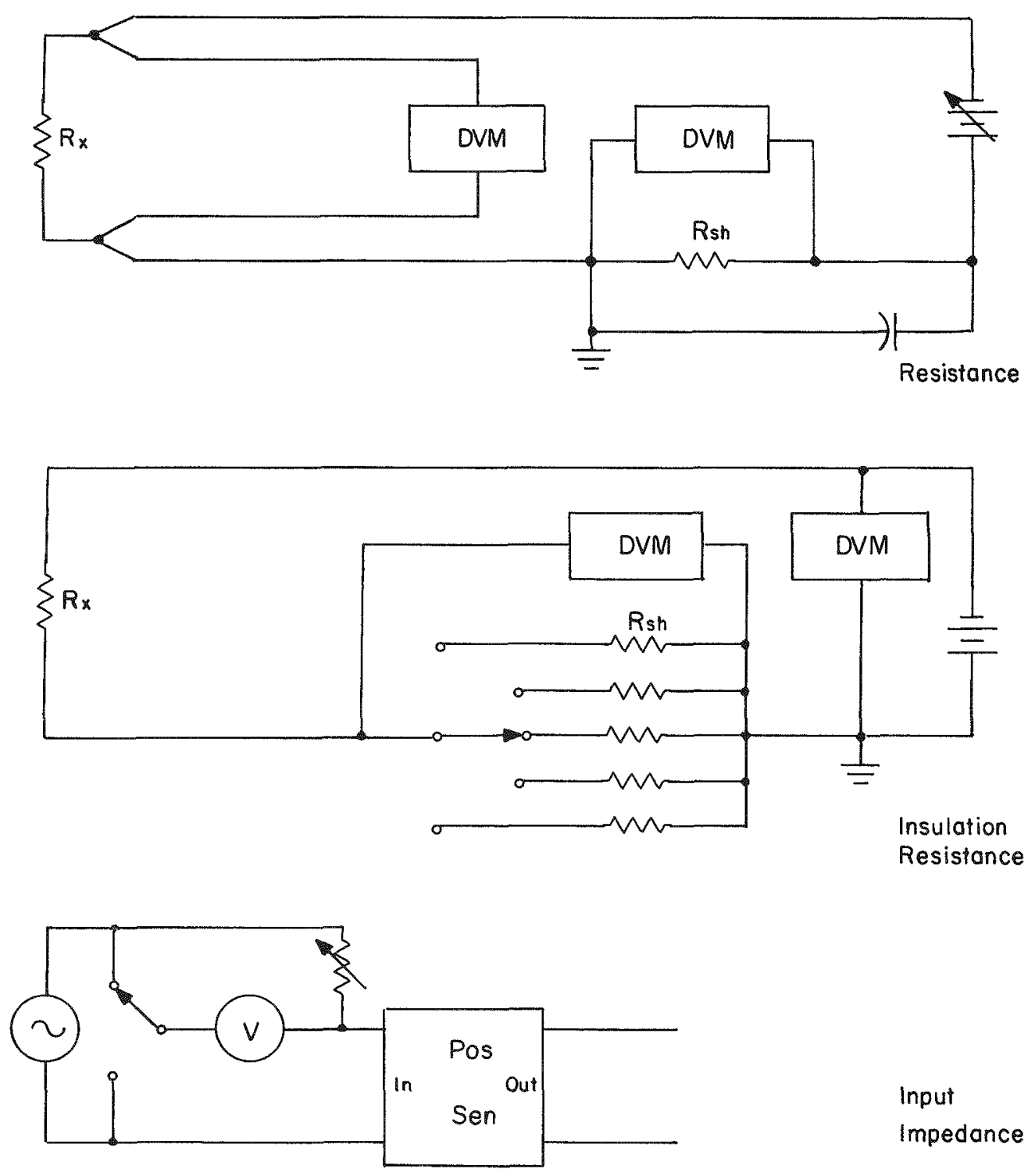

Input Impedance

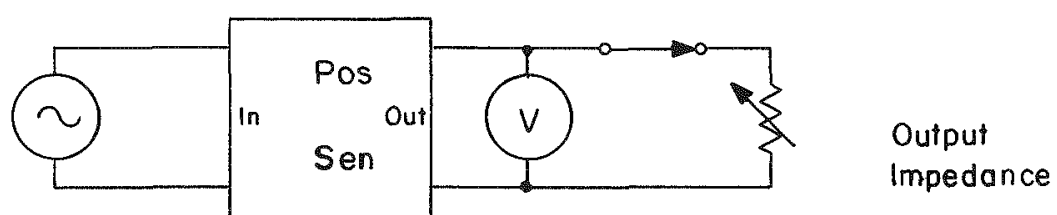

FIGURE 17. BASIC MEASURING CIRCUITS EMPLOYED IN EXPERIMENT HF-5 
resistance of the measurement leads between the instrument room and the top of the irradiation capsule (including all terminal blocks, connectors, etc.) was in the range from $10 \times 10^{9}$ to $30 \times 10^{9} \mathrm{ohms}$.

Resistance. Resistances were measured using the four-wire circuit shown in Figure 17. The junction of the current and potential leads was located at the top of the irradiation capsule, outside the vacuum seal. A shorted pair of dummy leads from the vacuum seal to the specimen area were measured every time measurements were made on the specimens. The resistance of this shorted pair of leads was then subtracted from the resistance measurements to compensate for lead resistance between the vacuum seal and the specimens. The four-wire circuit made compensation between the vacuum seal and the instrument room (approximately $60 \mathrm{ft}$ ) unnecessary.

Input Impedance. The input impedance of the position sensor was measured at $400 \mathrm{cps}$. The resistor shown in the circuit of Figure 17 was a decade resistance. Its value was adjusted until the vacuum-tube voltmeter read the same for both settings of the switch. The value of the decade resistance is the value recorded as input impedance.

Output Impedance. Output impedance was measured with a constant amplitude $400-c$ ps input applied to the position sensor. The output voltage was measured with the switch open. The switch was then closed and the decade resistor adjusted until the output voltage was one-half the value recorded with the switch open. The value of the decade resistance is the value recorded as output impedance.

Summary of Measurement Results

Insulation Resistance. The measured coil-insulation resistances for the upper and lower units are shown in Figures 18 and 19. The points plotted are for Thursday of each week during the irradiation. The final insulation resistance at pool ambient temperature is shown. The numbers on the various curves correspond to the following measurement points in each specimen:

21 - Actuator coil to ground

23 - Brake coil to ground

25 - Position sensor input coil to ground

27 - Position sensor output coil to ground

29 - Dummy leads to ground

33 - Magnetic pickup coil to ground

35 - Position sensor input to output coils. 


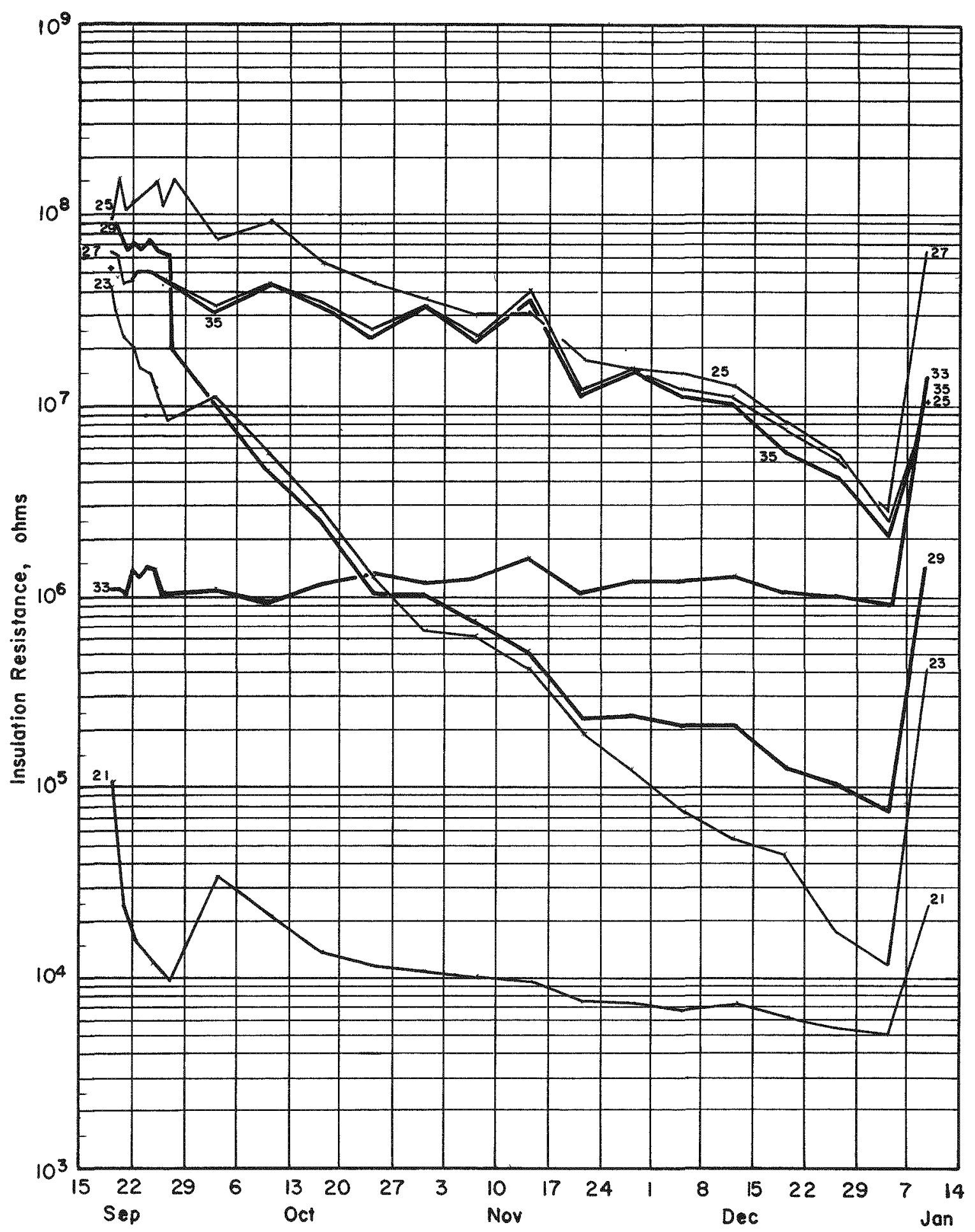

FIGURE 18. MEASURED COIL INSULATION RESISTANCES IN THE UPPER ASSEMBLY OF HF- 5 


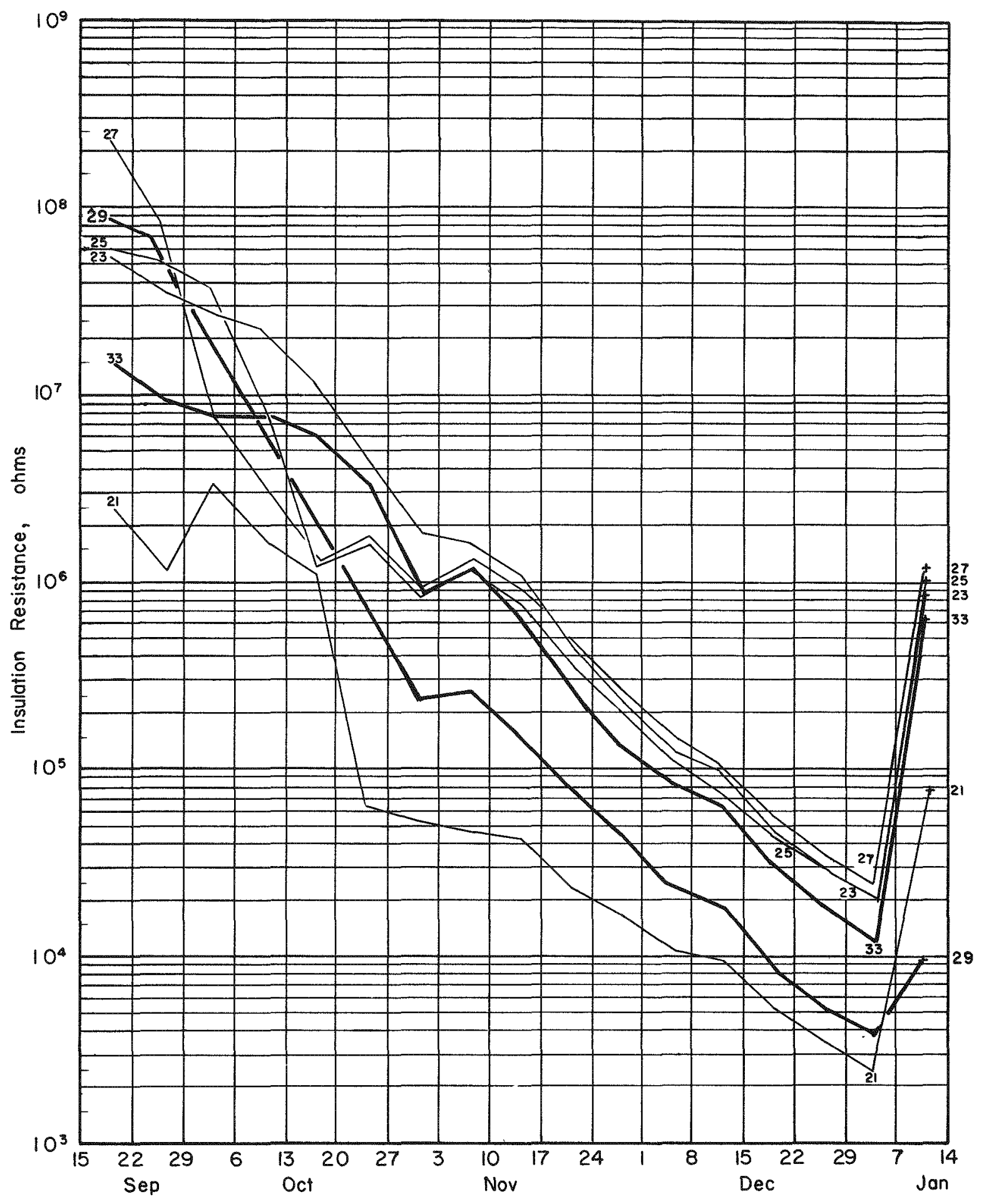

FIGURE 19. MEASURED COIL INSULATION RESISTANCES IN THE LOWER ASSEMBLY OF HF-5 
In Figure 19, curves 25 and 35 are very similar, and are presented as a single curve labeled 25.

Resistance. The coil-resistance measurements for the upper and lower units are shown in Figures 20 and 21. The initial and final measurements at pool ambient temperature are not shown because these resistance measurements are very temperature sensitive and would require some sort of normalization to be meaningful. The numbers on the curves correspond to the following measurement points in each specimen:

$$
\begin{aligned}
& 5 \text { - Actuator stator, Phase A } \\
& 7 \text { - Actuator stator, Phase B } \\
& 9 \text { - Actuator stator, Phase C } \\
& 11 \text { - Actuator stator, Phase D }
\end{aligned}
$$

Notice that Curve 11 is not shown in Figure 23. Curve 11 tracks Curve 5 very closely.

Position Sensor Input and Output Resistance and Impedance. The input and output resistances (dc) and impedances (400 cps) for the upper and lower units are shown in Figures 22 and 23. Notice that the scale factor of the output resistance plots in the two figures is different, whereas the scale factors for the other plots are the same, although the values of resistance differ.

Summary of Operation Results

Figures 24 through 27 show the outputs from the position transducers. The units were operated clockwise and counterclockwise for alternate measurements. The actual positions of the units were determined with magnetic pickups and toothed wheels with different width teeth and different spacings between the teeth. The magnetic pickup output was recorded on a strip chart and the actual position of each unit was determined by the pattern traced by the strip chart recorder. The readings did not vary greatly during the irradiation. The curves plotted in Figures 24 through 27 are for September 19 and 20. The distribution of later readings around these curves is shown by the histograms. Notice that the horizontal scale of the histograms is not to the same scale as the horizontal scale of the plots. The histograms were expanded $2-1 / 2$ times to make them more readable.

Summary of Specimen Radiation Exposures

Integrated radiation exposures for the test actuator assemblies were determined. from data obtained from both in-pile and mock-up dosimetry. Dosimeters were attached to the specimens at selected points during the in-pile operation. Nickel dosimeter wires were used to measure the integrated nickel threshold fluxes, which were then corrected to neutron exposures above $0.1 \mathrm{Mev}$ and $0.5 \mathrm{Mev}$ by the fast neutron spectrum measured 


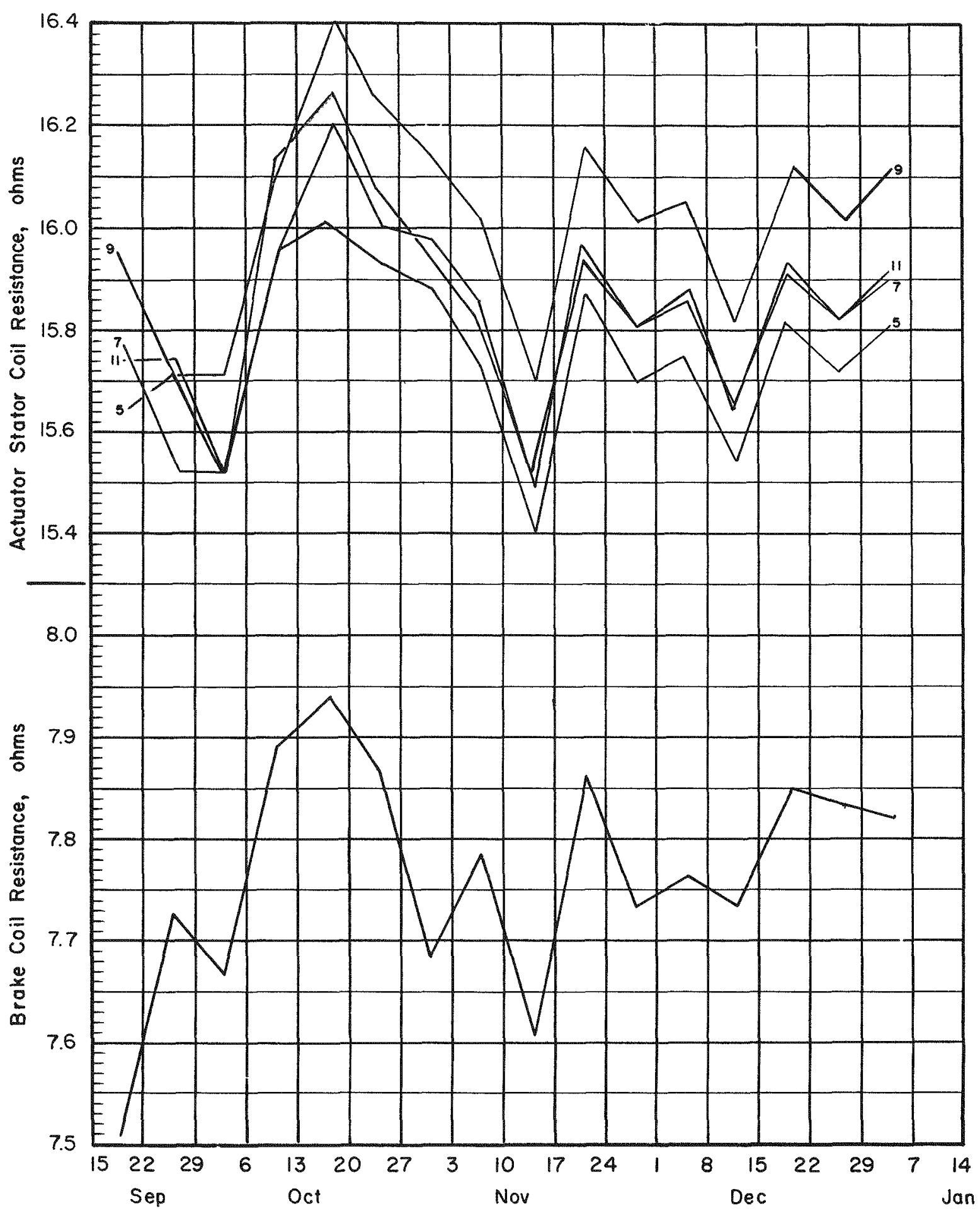

FIGURE 20. MEASURED COIL RESISTANCES IN THE UPPER ASSEMBLY OF HF-5 


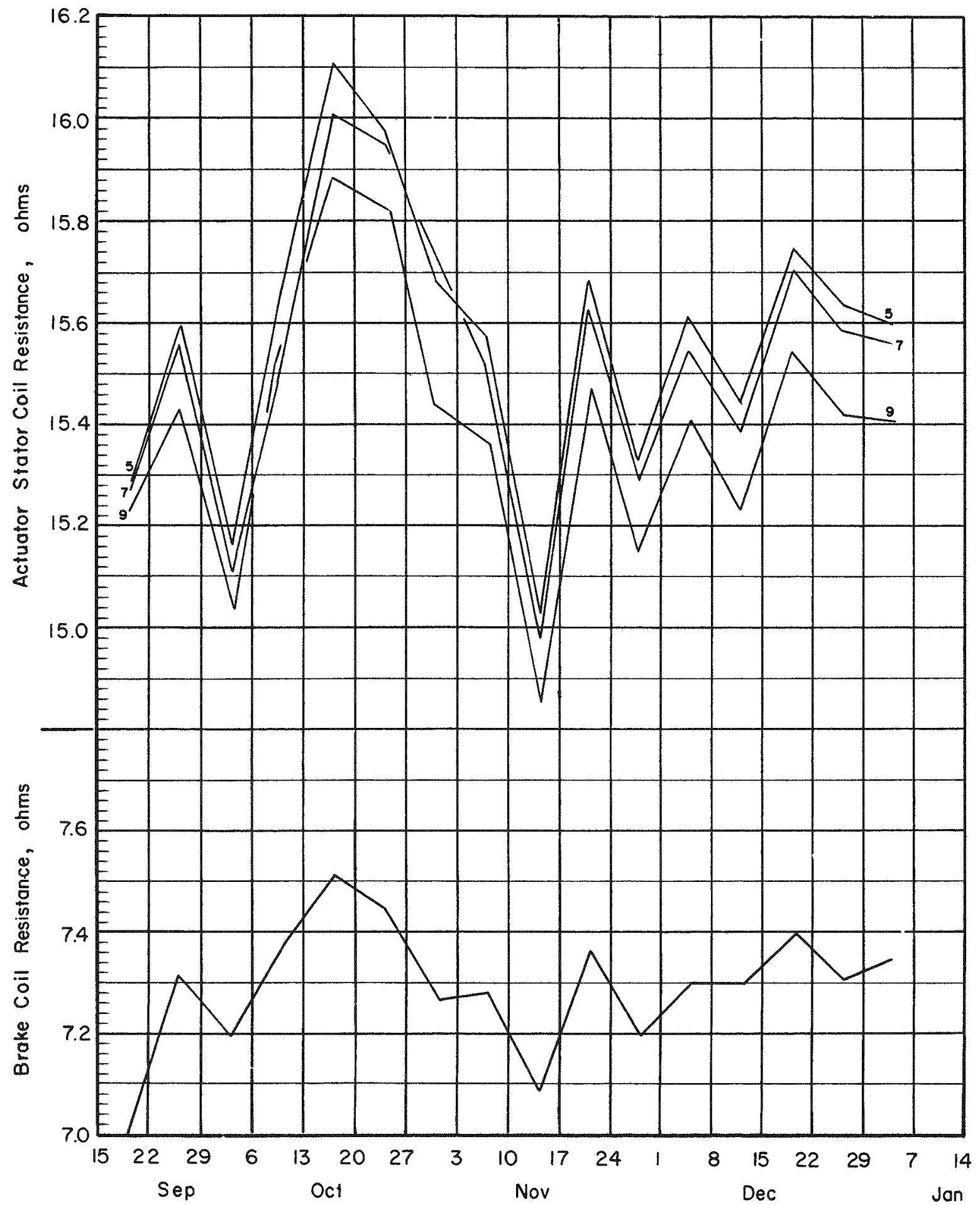

FIGURE 21. MEASURED COIL RESISTANCES IN THE LOWER ASSEMBLY OF HF-5 


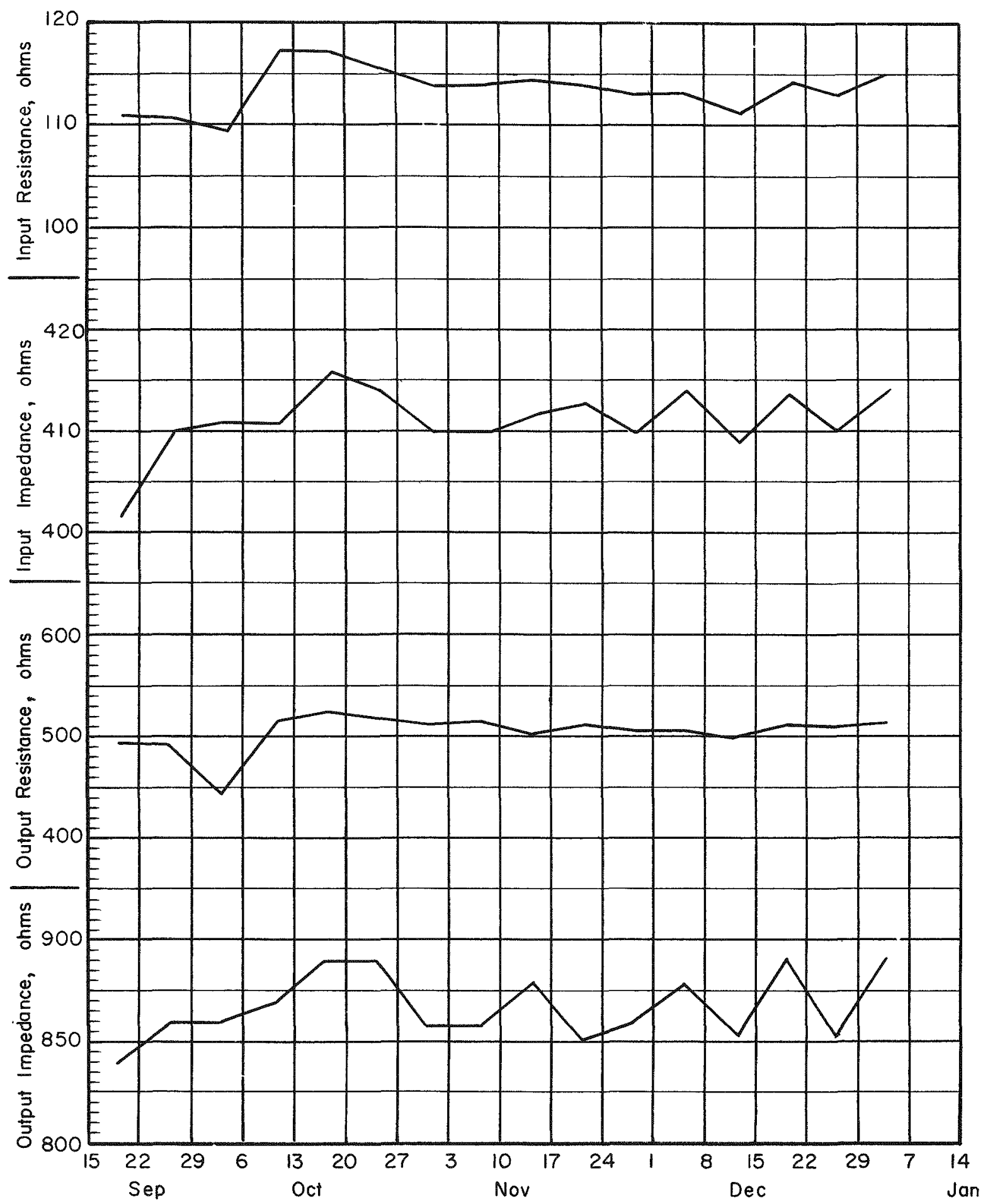

FIGURE 22. MEASURED POSITION SENSOR INPUT AND OUTPUT RESISTANCES AND IMPEDANCES IN THE UPPER ASSEMBLY OF HF- 5 


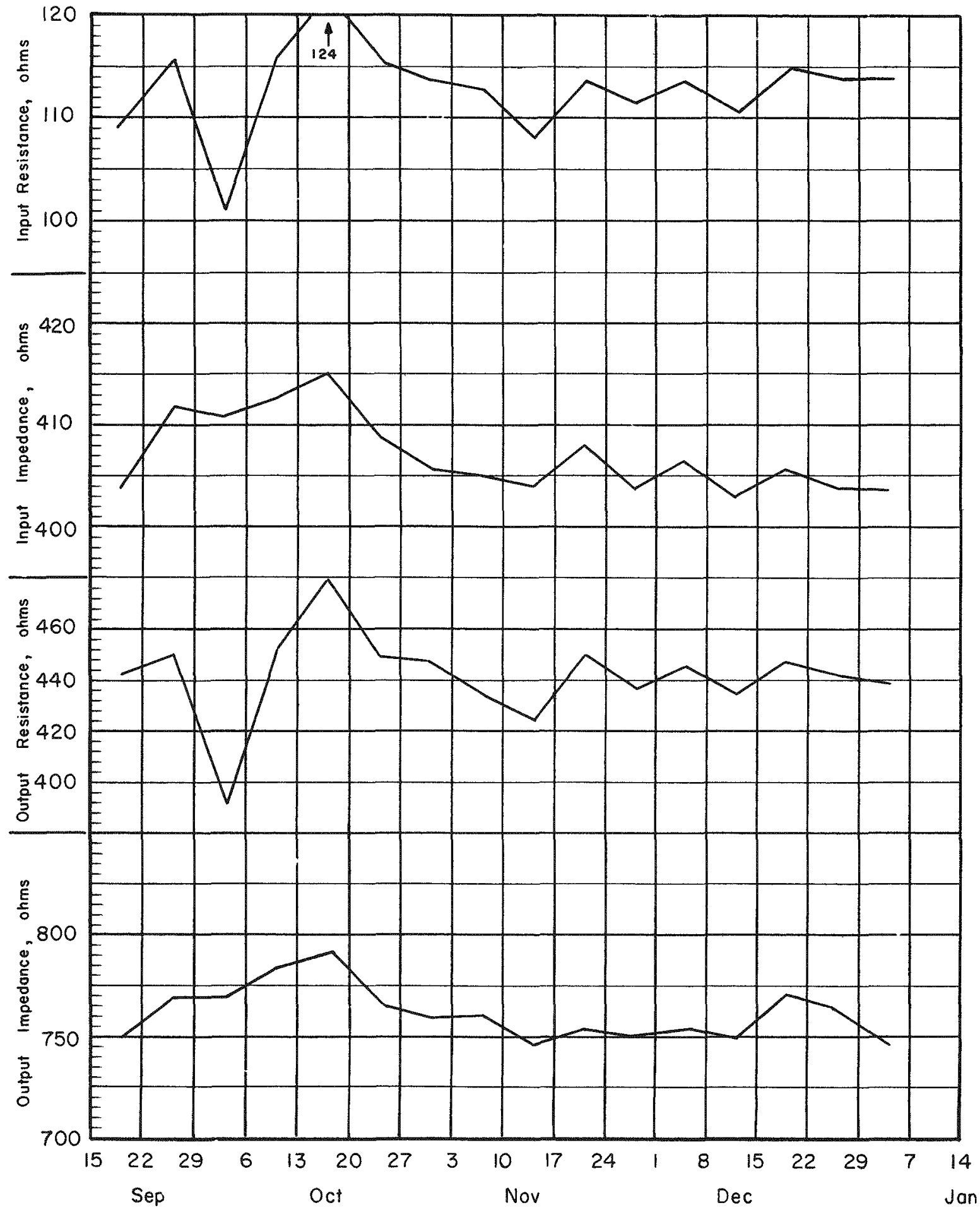

FIGURE 23. MEASURED POSITION SENSOR INPUT AND OUTPUT RESISTANCES AND IMPEDANCES IN THE LOWER ASSEMBLY OF HF- 5 


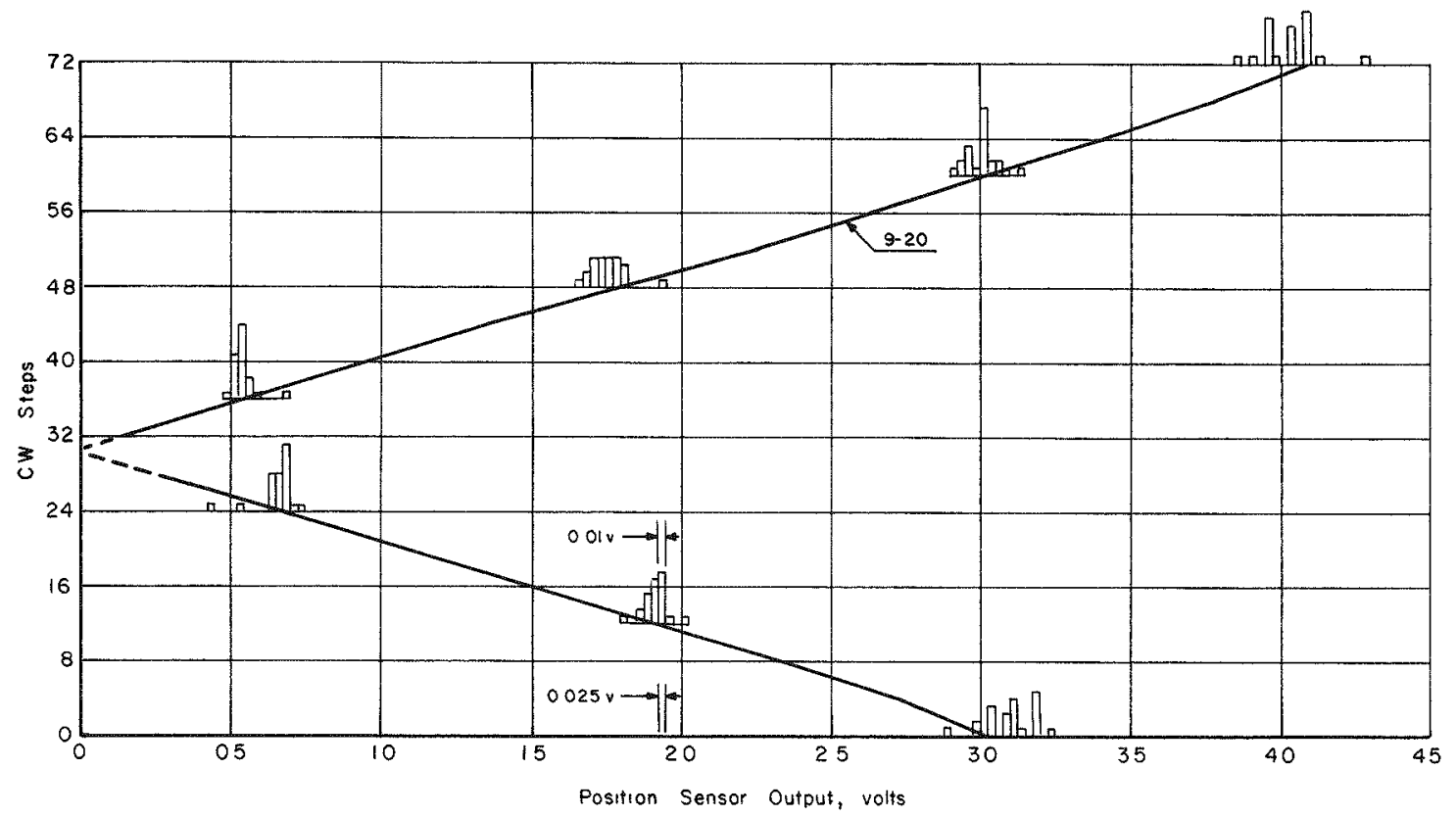

FIGURE 24. POSITION SENSOR OUTPUT FOR CLOCKWISE STEPPING OF THE UPPER ACTUATOR IN HF- 5

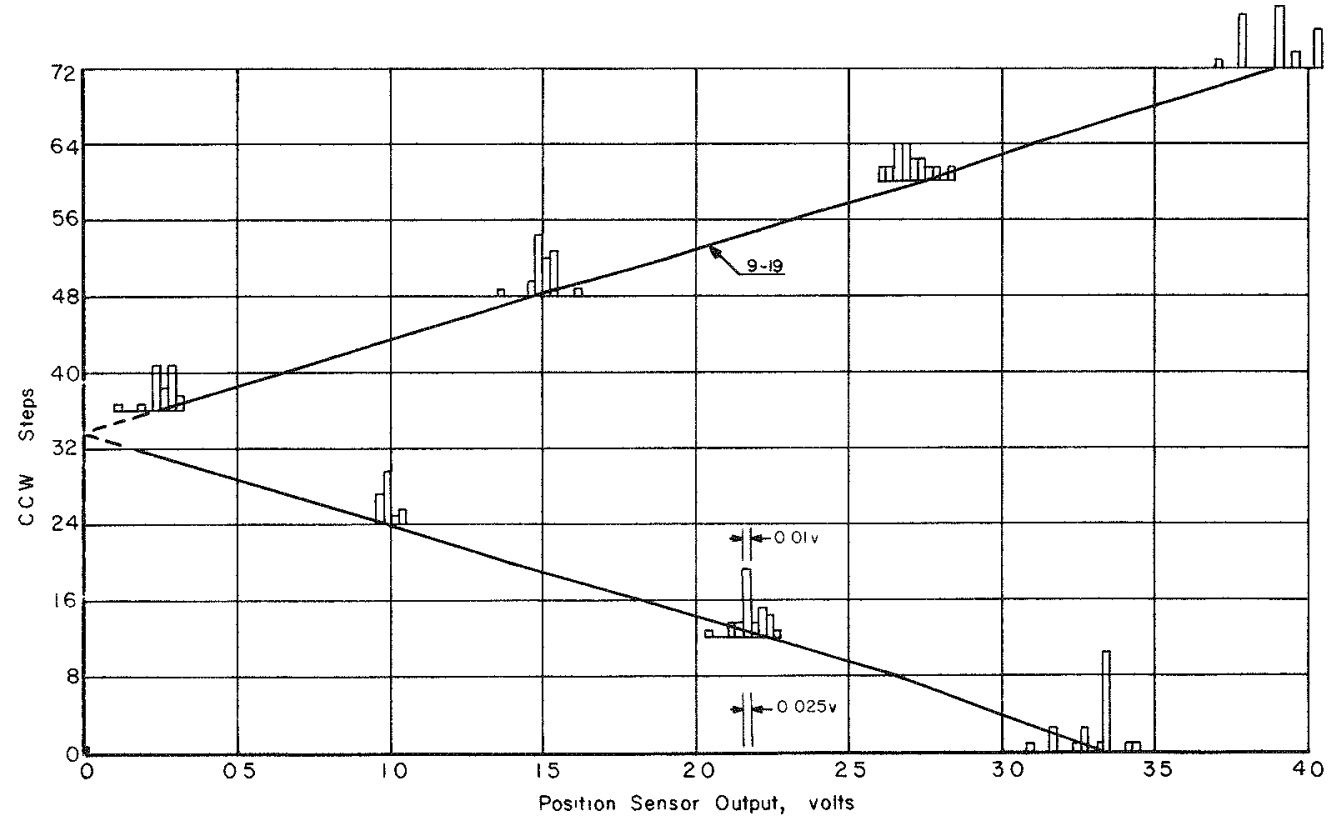

FIGURE 25. POSITION SENSOR OUTPUT FOR COUNTER-CLOCKWISE STEPPING OF THE UPPER ACTUATOR IN HF- 5 


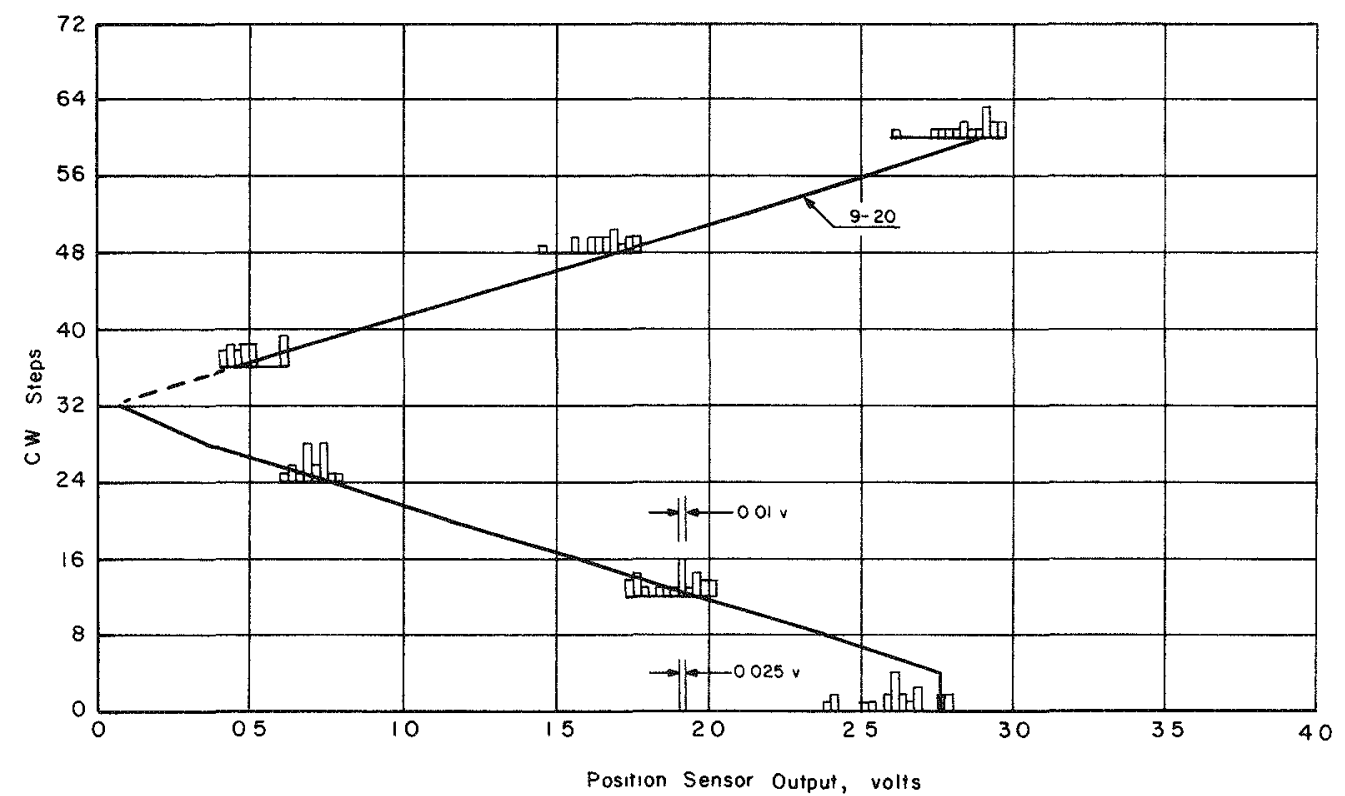

FIGURE 26. POSITION SENSOR OUTPUT FOR CLOCKWISE STEPPING OF THE LOWER ACTUATOR IN HF-5

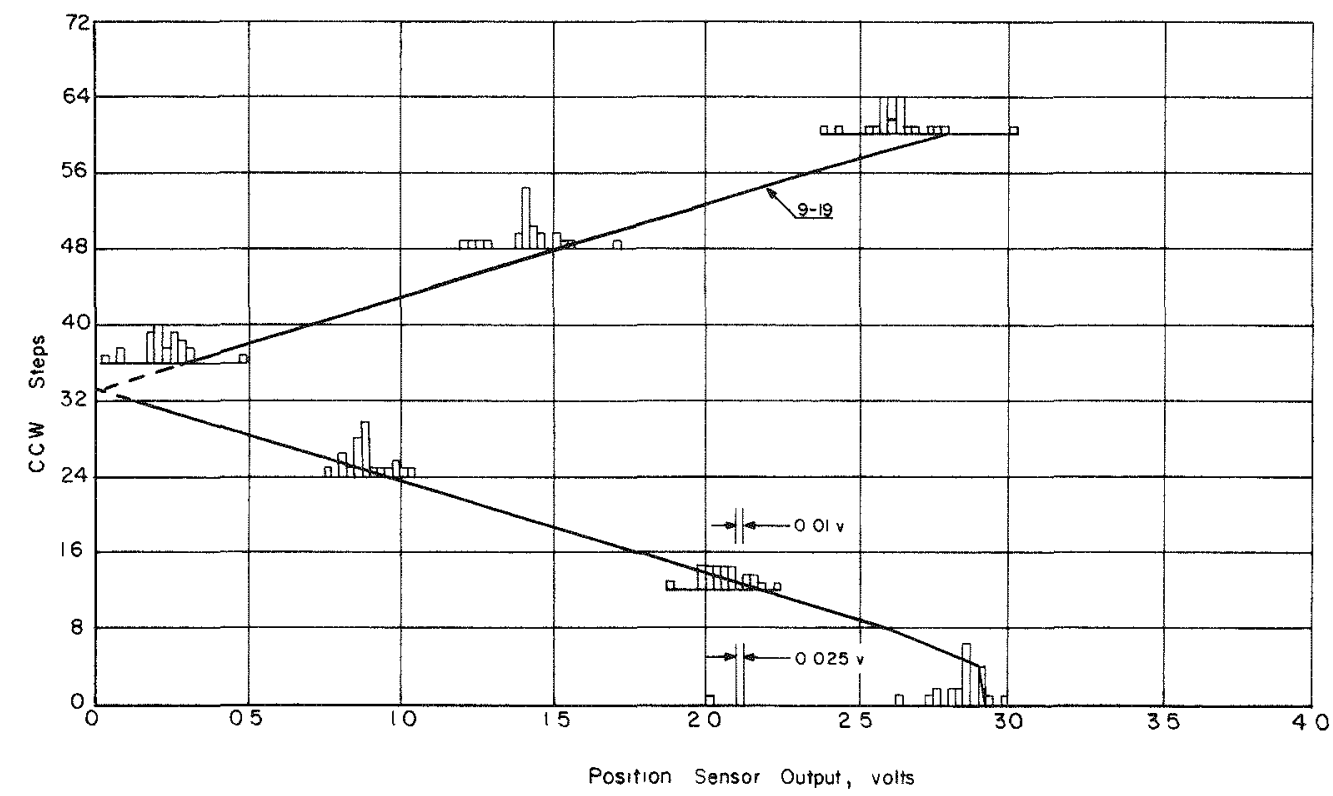

FIGURE 27. POSITION SENSOR OUTPUT FOR COUNTER-CLOCKWISE STEPPING OF THE LOWER ACTUATOR IN HF-5 
in the mock-up dosimetry. Cobalt-aluminum dosimeter wires $(0.75 \mathrm{w} / \mathrm{o}$ cobalt) were employed to obtain the integrated thermal neutron fluxes. Integrated resonance neutron fluxes were calculated from the measured fast-neutron exposures by using the ratios of resonance-to-fast neutron fluxes measured in the mock-up dosimetry. The neutron exposures of internal parts of the actuators were determined from these measured external exposures and correlations between external and internal fluxes established in the mock-up work. Gamma exposures were calculated from the exposure rates measured in the mock-up and the specimen exposure times.

The average in-pile radiation exposures received by each actuator are given in Table 6, along with the exposures specified and those predicted from the mock-up results. The predicted exposures are based on mock-up measurements made in an unperturbed nuclear environment and on an uninterrupted eight-cycle irradiation, and the actual exposures can be expected to be less than the predictions.

TABLE 6. AVERAGE RADIATION EXPOSURES FOR TEST ACTUATORS

\begin{tabular}{|c|c|c|c|}
\hline & Specified & $\begin{array}{c}\text { Exposures } \\
\text { Mock-Up }\end{array}$ & In-Pile \\
\hline \multicolumn{4}{|l|}{ Upper Actuator Assembly } \\
\hline Fast Neutrons, $\mathrm{n}$ per $\mathrm{cm}^{2}$ & $4.06 \times 10^{18}$ & $3.3 \times 10^{18}$ & $2.21 \times 10^{18}$ \\
\hline Resonance Neutrons, $\mathrm{n}$ per $\mathrm{cm}^{2}$ & $4.06 \times 10^{18}$ & $23 \times 10^{18}$ & $1.03 \times 10^{18}$ \\
\hline Thermal Neutrons, $\mathrm{n}$ per $\mathrm{cm}^{2}$ & $8.13 \times 10^{17}$ & $3.2 \times 10^{18}$ & $1.76 \times 10^{18}$ \\
\hline Gamma, $\mathrm{R}$ & $4.06 \times 10^{9}$ & $4.3 \times 10^{9}$ & $3.19 \times 10^{9}$ \\
\hline \multicolumn{4}{|l|}{ Lower Actuator Assembly } \\
\hline Fast Neutrons, $\mathrm{n}$ per $\mathrm{cm}^{2}$ & $4.06 \times 10^{18}$ & $7.6 \times 10^{18}$ & $4.03 \times 10^{18}$ \\
\hline Resonance Neutrons, $\mathrm{n}$ per $\mathrm{cm}^{2}$ & $4.06 \times 10^{18}$ & $3.9 \times 10^{18}$ & $2.00 \times 10^{18}$ \\
\hline Thermal Neutrons, $\mathrm{n}$ per $\mathrm{cm}^{2}$ & $8.13 \times 10^{17}$ & $5.1 \times 10^{18}$ & $3.38 \times 10^{18}$ \\
\hline Gamma, $\mathrm{R}$ & $4.06 \times 109$ & $7.5 \times 109$ & 5. $28 \times 109$ \\
\hline
\end{tabular}

Exposures for the components of the two test actuators are given in Table 7. Neutron exposures are broken down into four groups: Group I - the thermal-neutron exposures (0 to $0.4 \mathrm{ev})$; Group II - the resonance-neutron exposures $(0.4 \mathrm{ev}$ to $0.1 \mathrm{Mev}$ ); Group III - the fast-neutron exposures from 0.1 to $0.5 \mathrm{Mev}$ which were obtained by subtracting the fast-neutron exposures above $0.5 \mathrm{Mev}$ from the total fastneutron exposures; Group IV - the fast-neutron exposures above $0.5 \mathrm{Mev}$. 
TABLE 7. COMPONENT NEUTRON AND GAMMA EXPOSURES

\begin{tabular}{|c|c|c|c|c|c|}
\hline & \multicolumn{5}{|c|}{ Exposures } \\
\hline & $10^{18} \mathrm{~N}$ per $\mathrm{Cm}^{2}$ & $\begin{array}{c}\text { Group II } \\
10^{18} \mathrm{~N} \text { per } \mathrm{Cm}^{2}\end{array}$ & $\begin{array}{c}\text { Group III } \\
10^{18} \mathrm{~N} \text { per } \mathrm{Cm}^{2}\end{array}$ & $\begin{array}{c}\text { Group IV } \\
10^{18} \mathrm{~N} \text { per } \mathrm{Cm}^{2}\end{array}$ & $\begin{array}{c}\text { Gamma } \\
10^{9} \mathrm{R}\end{array}$ \\
\hline Lower Actuator Assembly & & & . & & \\
\hline Position sensor case & 3.85 & 2.08 & 1.08 & 2.78 & 4.84 \\
\hline Position sensor coil & 3.85 & 2.08 & 1.08 & 2.78 & 4.84 \\
\hline Magnetic pickup case & 3.62 & 2.22 & 1.26 & 3.26 & 5.40 \\
\hline Magnetic pickup coil & 3.62 & 2.13 & 1.20 & 3.12 & 5.40 \\
\hline Bearing, position sensor end & 3.62 & 2.18 & 1.23 & 3.19 & 5.40 \\
\hline Actuator case & 3.26 & 1.86 & 1.08 & 2.81 & 5.49 \\
\hline Actuator coil & 3.26 & 1.80 & 1.05 & 2.72 & 5.49 \\
\hline Brake case & 2.84 & 1.85 & 1.06 & 2.76 & 5.38 \\
\hline Brake coil & 2.84 & 1.85 & 1.06 & 2.76 & 5.38 \\
\hline Connector & 3.01 & 1.98 & 1.12 & 2.91 & 5.15 \\
\hline \multicolumn{6}{|l|}{ Upper Actuator Assembly } \\
\hline Position sensor case & 0.92 & 0.47 & 0.27 & 0.71 & 1.87 \\
\hline Position sensor coil & 0.92 & 0.47 & 0.27 & 0.71 & 1.87 \\
\hline Magnetic pickup case & 1.53 & 1.01 & 0.59 & 1.54 & 2.70 \\
\hline Magnetic pickup coil & 1.53 & 0.96 & 0.57 & 1.47 & 2.70 \\
\hline Bearing, position sensor end & 1.53 & 0.98 & 0.58 & 1.50 & 2.70 \\
\hline Actuator case & 1.94 & 1.12 & 0.67 & 1.72 & 3.52 \\
\hline Actuator coil & 1.94 & 1.09 & 0.65 & 1.68 & 3.52 \\
\hline Brake case & 2.32 & 1.35 & 0.79 & 2.04 & 4.17 \\
\hline Brake coil & 2.32 & 1.35 & 0.79 & 2.04 & 4.17 \\
\hline Connector & 2.64 & 1.50 & 0.97 & 2.52 & 4.68 \\
\hline
\end{tabular}

